\title{
Recent advances in solid-phase sorbents for sample preparation prior to chromatographic analysis
}

\author{
Yingying Wen a,b,c, Ling Chen ${ }^{\mathrm{a}, \mathrm{c}}$, Jinhua $\mathrm{Li}^{\mathrm{a}}{ }^{\mathrm{a}}$, Dongyan Liu ${ }^{\mathrm{a}}$, Lingxin Chen ${ }^{\mathrm{a}, *}$ \\ a Key Laboratory of Coastal Environmental Processes and Ecological Remediation, Yantai Institute of Coastal Zone Research, Chinese Academy of Sciences, \\ Yantai 264003, China \\ b Laboratory of Environmental Monitoring, School of Tropical and Laboratory Medicine, Hainan Medical University, Haikou 571199, China \\ c University of Chinese Academy of Sciences, Beijing 100049, China
}

\section{A R T I C L E I N F O}

\section{Keywords:}

Carbon nanomaterial

Chromatographic analysis

Matrix solid-phase dispersion

Metallic nanoparticle

Metal organic framework

Molecularly-imprinted polymer

Sample preparation

Solid-phase extraction

Solid-phase microextraction

Solid-phase sorbent (SPS)

\begin{abstract}
A B S T R A C T
Sample preparation is a crucial bottleneck in the whole analytical process. Solid-phase sorbents (SPSs) have aroused increasing interest in research on sample preparation, as they have key roles in obtaining high clean-up and enrichment efficiency in the analysis of trace targets present in complex matrices. The objective of this review is to provide a broad overview of the recent advances and applications of SPSs in sample preparation prior to chromatographic analysis, during the period 2008-13. We include SPSs, such as molecularly-imprinted polymers, carbon nanomaterials, metallic nanoparticles and metal organic frameworks, focusing on solid-phase extraction, solid-phase microextraction, matrix solid-phase dispersion and stir-bar sorptive extraction of typical pollutants in environmental, biological, food and pharmaceutical samples. We propose remaining challenges and future perspectives to improve development of new SPSs and to apply them further.
\end{abstract}

(C) 2014 Elsevier B.V. All rights reserved.

Contents

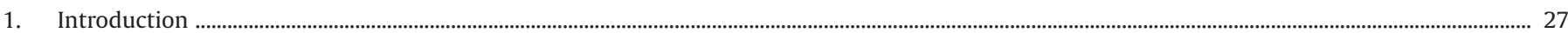

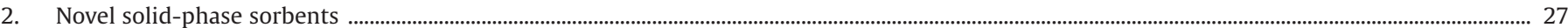

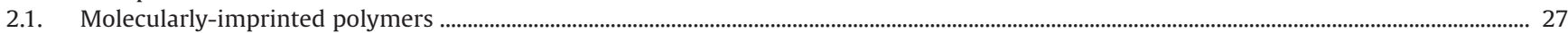

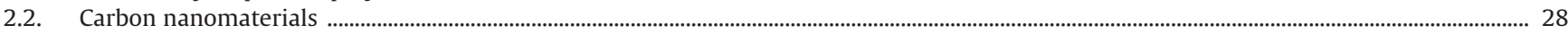

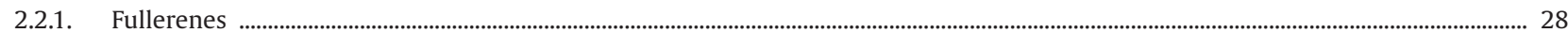

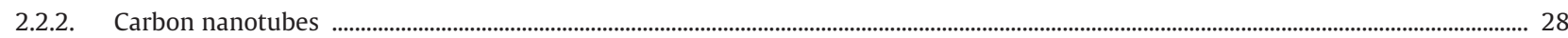

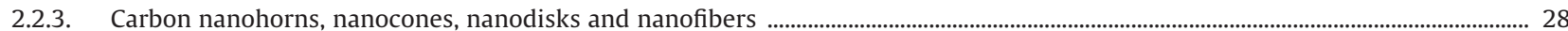

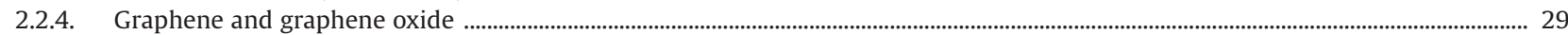

2.3. Metallic nanoparticles ........................... 29

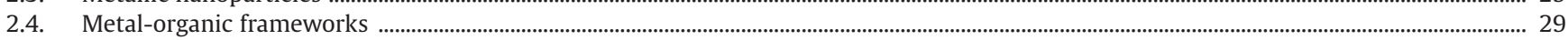

3. Solid-phase sorbents for sample preparation prior to chromatographic analysis .......................................................................................................... 29

3.1. Molecularly-imprinted polymers as solid-phase sorbents ………………………………………………………………………………………….... 29.

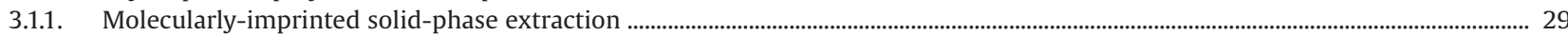

3.1.2. Solid-phase microextraction, matrix solid-phase dispersion and stir-bar sorptive extraction ............................................................. 31

Abbreviations: 2- or 4-VP, 2- or 4-vinylpyridine; AA, Acrylic acid; APTES, Aminosilica monomer; BPA, Bisphenol A; CNT, Carbon nanotube; CP, Chlorophenol; CTAB,

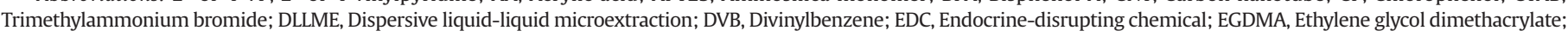

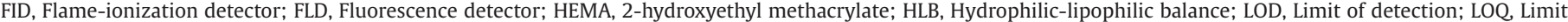

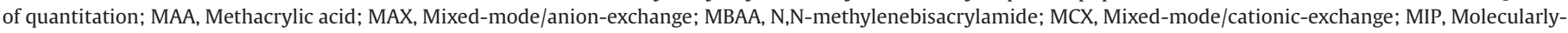

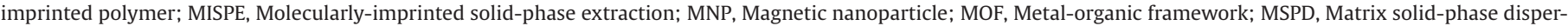

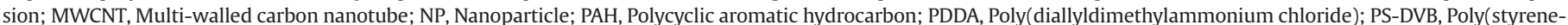

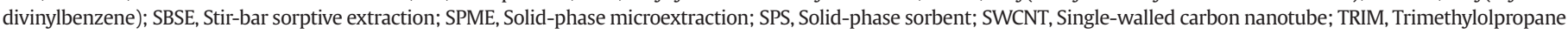
trimethacrylate; WAX, Weak anion-exchange.

* Corresponding author. Tel.: +86 535 2109130; Fax: +86 5352109130.

E-mail address: lxchen@yic.ac.cn (L. Chen). 


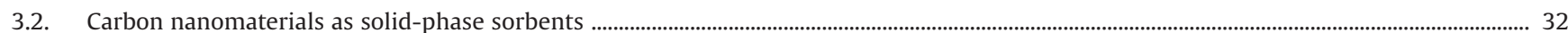

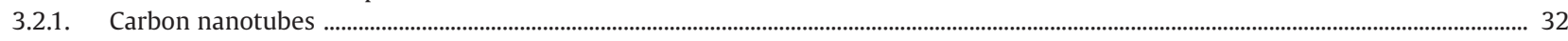

3.2.2. Graphene, graphene oxide and other carbon nanomaterials _.............................................................................................................. 35

3.3. Metallic nanoparticles as solid-phase sorbents ................................................................................................................................................... 35

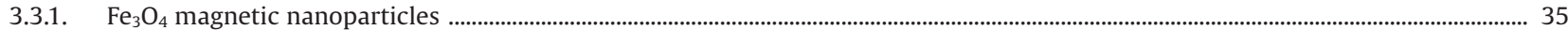

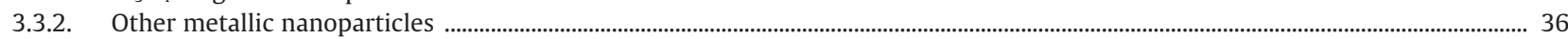

3.4. Metal-organic frameworks as solid-phase sorbents ................................................................................................................................................ 36

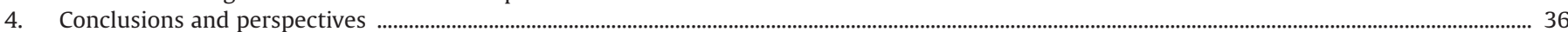

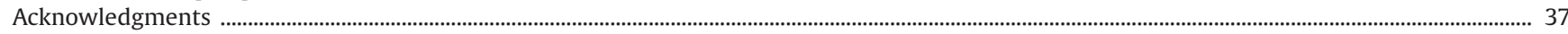

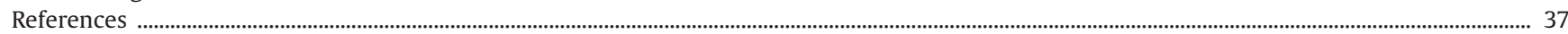

\section{Introduction}

Sample preparation is a crucial part of chemical/biological analysis and in a sense is considered the bottleneck of the whole analytical process. The main objectives of sample preparation are the removal of potential interferences, analyte preconcentration, and converting (if needed) the analyte into a more suitable form for detection or separation. In recent decades, solid-phase extraction (SPE) has played a crucial role in sample preparation, replacing the classic liquid-liquid extraction (LLE), in environmental, food and biological analyses [1-3]. In the past, some classic materials, such as $C_{8}$, $\mathrm{C}_{18}$, hydrophilic-lipophilic balance (HLB, the sorbent of which is a macroporous copolymer made from a balanced ratio of two monomers including hydrophilic and lipophilic ones), mixed-mode/ cationic-exchange (MCX), mixed-mode/anion-exchange (MAX) and weak anion-exchange (WAX) were commonly used for SPE [4]. More recently, a large number of new solid-phase sorbents (SPSs), such as molecularly-imprinted polymers (MIPs) [5], magnetic nanomaterials [6] and carbon nanoparticles (NPs) [7] have been proposed and applied for sample preparation. Moreover, although some powerful techniques (including HPLC-MS/MS and GC-MS/MS) are also subjected to improving the detectability for analytes in complex matrices, new objectives of sample preparation have been set, such as using small initial volume or weight of sample, improvement of selectivity in extraction, facilitating automation, and minimizing the amount of glassware and organic solvents to be used. Thus, some other sample-preparation methodologies, such as solid-phase microextraction (SPME), stir-bar sorptive extraction (SBSE) and matrix solid-phase dispersion (MSPD), have been effective for the above purposes. These methods, together with SPE, stimulated rapid advances of the new SPSs. A number of research efforts dealing with novel SPSs specifically developed for these applications in chromatography have been reported and some have been reviewed.

Lucena et al. [7] gave a general overview of the use of NPs mainly including carbon, metallic, silica and imprinted NPs to perform sample preparation in SPE and SPME.

Turiel and Martín-Esteban [8,9] reviewed the use of MIPs in SPE, SPME, MSPD and SBSE.

Augusto et al. [10] outlined progress in research on some new classes of sorbents, such as carbon nanotubes (CNTs), MIPs and solgel coatings for SPME fibers and related techniques, and for extraction and microextraction techniques.

Tankiewicz et al. [11] described some SPSs applied in SPE, SPME and SBSE.

Several recent reviews were released in 2013. For example, Mehdinia and Aziz-Zanjani [12] reviewed advances for sensitive, rapid and selective extraction in different configurations of SPME, containing some new SPSs.

Spieteluna et al. [13] summarized recent developments and future trends in SPME toward green analytical chemistry containing various novel SPSs.

Yang et al. [14] presented an overview of microextraction techniques for the determination of volatile and semi-volatile organic compounds from plants, involving SPS preparation and applications.
Namera and Saito [15] reviewed some new SPSs used in SPE and SPME methods for bioanalysis.

An important trend shared by the fundamental research on the above extraction techniques relates to the development and the characterization of new sorbents. It has become a hot issue to research new advanced materials, involving several branches of disciplines, such as materials science, nanotechnology, polymer synthesis and analytical chemistry. The development of SPSs generally aims for: high selectivity, good sorptive/adsorptive capacity, enhanced thermal, chemical or mechanical stability and improved lifetime of devices employing them as sorbent/adsorbent media [10]. In this review, we therefore provide an updated, essential summary of the most important features and applications of new materials as SPSs in SPE, SPME, MSPD and SBSE prior to chromatographic analysis. We summarize highlighted applications of these new SPSs for the extraction of environmental, biological, food and pharmaceutical samples. We also discuss the present limitations and expected future trends of SPSs in sample preparation for better advancement.

\section{Novel solid-phase sorbents}

Traditional SPSs, such as silica NPs, $\mathrm{C}_{8}, \mathrm{C}_{18}$, poly (styrenedivinylbenzene) (PS-DVB), methacrylate-DVB resins, macroporous poly ( $\mathrm{N}$-vinylpyrrolidone-DVB) polymers and some others, usually used mixed-mode ion-exchange sorbents, including MCX, MAX and WAX, which have already been reviewed in detail by Alberti et al. [4]. The present review focuses on the preparation and the applications of novel SPSs, mainly including MIPs, carbon nanomaterials, metallic NPs and metal-organic frameworks (MOFs).

\subsection{Molecularly-imprinted polymers}

In recent years, MIPs proved to be useful materials in several areas of analytical chemistry [5,16-20]. MIPs are synthetic materials with artificially-generated recognition sites able to specifically rebind a target molecule in preference to other closely-related compounds. Functional monomers and cross-linking agents are copolymerized in the presence of a template (the imprint molecule) in a suitable solvent, leading to a highly cross-linked three-dimensional network polymer. The monomers are chosen by considering their ability to interact with the functional groups of the template molecule. Subsequent removal of the imprint molecule leaves cavities with size, shape and chemical functionality complementary to those of the template. The inherently high selectivity associated with MIPs has made them ideal sorbents to be used in SPE, SPME, MSPD and SBSE [18]. Recently, our group reviewed recent advances in molecular imprinting technology, with particular emphasis on significant progress of novel imprinting methods and MIP materials, some challenges and effective strategies, and highlighted applications of MIPs [5].

The mechanism of MIP formation mainly includes free-radical polymerization and the sol-gel process. Use of free-radical polymerization became popular recently, including bulk polymerization, suspension polymerization, emulsion polymerization, seed polymerization and precipitation polymerization. During 
polymerization, the types of target molecule, monomer and crosslinker have an important effect. First, an ideal template molecule plays a key role in the polymerization. Nowadays, hormone drugs, triazine pesticides and phenolic compounds, such as bisphenol A (BPA), are the most widely used targets in preparing MIPs. The role of the monomer is to provide functional groups that can form a complex with the template by covalent or non-covalent interactions. For molecular imprinting, methacrylic acid (MAA), acrylic acid (AA), 2- or 4-vinylpyridine (2- or 4-VP), acrylamide, trifluoromethacrylic acid and 2-hydroxyethyl methacrylate (HEMA) are commonly used monomers. The role of the cross-linker is to fix functional groups of monomers around imprinted molecules, and thereby form highly cross-linked rigid polymers. Commonly used cross-linkers include ethylene glycol dimethacrylate (EGDMA), trimethylolpropane trimethacrylate (TRIM), N,N-methylenebisacrylamide (MBAA) and divinylbenzene (DVB) [5].

\subsection{Carbon nanomaterials}

Since the discovery of fullerene $C_{60}$ in 1985 [21], carbon nanomaterial-based technology has developed as one of the most important trends in SPE. Carbon exists in a number of allotropic forms, such as fullerenes, CNTs, including single-walled CNTs (SWCNTs) and multi-wall CNTs (MWCNTs), carbon nanohorns, carbon nanocones, carbon nanodisks, carbon nanofibers, nanotube rings, graphene oxide (GO) and graphene (G), and diamonds [22-26]. However, to date, from the analytical point of view, the applications have mainly been focused on the use of fullerenes, CNTs and $\mathrm{GO} / \mathrm{G}$.

\subsubsection{Fullerenes}

Fullerenes are polyhedral nanostructures, in which carbons are bonded in arrangements of five-to-six-membered rings [7]. Although they are extremely insoluble in aqueous and organic media, their lower aggregation tendency facilitates their use as sorbents in miniaturized SPE procedures based on continuous-flow devices.

Gallego et al. [27] first fabricated a continuous-flow system, sorbed on a $\mathrm{C}_{60}$ fullerene mini-column for preconcentration of trace metals.

Serrano and Gallego [28] compared $\mathrm{C}_{60}$ fullerene, Tenax TA (a porous polymer resin based on 2.6-diphenylene oxide), and $\mathrm{RP}-\mathrm{C}_{18}$ as SPE sorbents for the extraction of benzene, toluene, ethyl benzene and xylene isomers from water samples. The results showed $C_{60}$ fullerene was the best choice in terms of sensitivity, precision, selectivity and reusability.

Recently, Jurado-Sánchez et al. [29] used fullerenes as SPSs in SPE for discrimination of aromatic and non-aromatic N-nitrosamines. An automatic SPE unit containing two sequential sorbent columns was constructed, and a comparative study of $C_{60}$ and $C_{70}$ fullerenes and nanotubes revealed $C_{60}$ fullerene to be the best choice to retain the aromatic fraction selectively. Hence, the simple, fast SPE system (10 min per sample) coupled with a customary GC-MS instrument permitted quantification of these amines in complex matrices with considerable sensitivity and selectivity [29].

\subsubsection{Carbon nanotubes}

CNTs can be viewed as graphite sheets ( $\mathrm{sp}^{2}$ carbon) that have been rolled up into tiny tubes. CNTs usually have a diameter in the range from a few tenths to tens of nanometers and a length up to centimeters [30]. Thanks to their large surface area-to-volume ratios and high affinity, CNTs can be considered as excellent materials for SPSs [7]. There are basically two types of CNTs: MWCNTs (including two or more concentric cylindrical shells or G sheets coaxially arranged around a central core) and SWCNTs [30]. Both of them have exhibited excellent adsorption properties as SPSs. The first application of CNTs was that MWCNTs were used for SPE and highly efficient enrichment was successfully achieved for BPA, 4-nnonylphenol and 4-tert-octylphenol from environmental water samples [31]. Recent advances of CNTs as SPSs (e.g., applied in SPE and SPME) were demonstrated by several excellent reviews $[4,7,30]$.

\subsubsection{Carbon nanohorns, nanocones, nanodisks and nanofibers}

As well as CNTs, carbon nanohorns, nanocones, nanodisks and nanofibers are also rapidly evolving as sorptive materials and (pseudo) stationary phases in modern separation sciences because of their unique physicochemical and mechanical properties and large chemically active surface areas. These carbon-based nanomaterials applied in sample preparation have been excellently reviewed in detail by Lin and his co-workers lately [32].

Carbon nanocones were first synthesized by vapor condensation of carbon atoms on a graphite substrate in 1994 [33] and the allotropic forms were identified in 1997 [34]. The discrimination of each structure corresponds to the presence of a given number of pentagons in the seed from which it grew, including disks (no pentagons), five types of cones (1-5 pentagons, as shown in Fig. 1) and open tubes (six pentagons) [23].

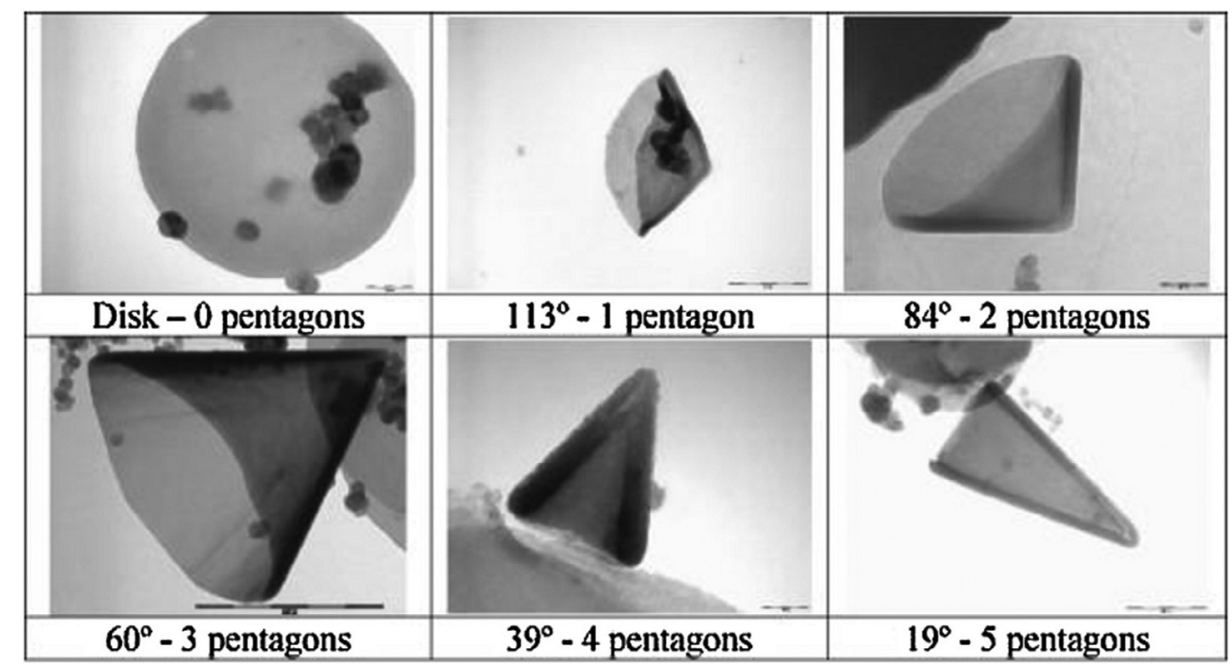

Fig. 1. Angles formed at the vertex of the carbon nanocones depending on the number of existing pentagons. (Reprinted with permission from [23]. @ 2013 Elsevier). 
Carbon nanofibers are solid carbon fibers with lengths in the order of a few microns and diameters below $100 \mathrm{~nm}$, and specific surface area reported up to $1877 \mathrm{~m}^{2} / \mathrm{g}$, the highest ever reported for nanostructured materials [35].

\subsubsection{Graphene and graphene oxide}

$\mathrm{G}$, an atomically thin honeycomb lattice of carbon atoms, recently sparked great excitement in the scientific community shortly after being discovered by Geim et al. in 2004 [36]. It attracted intensive interest in recent years due to its remarkable electronic, mechanical, optical and thermal properties [37], which make it the most promising carbon-based nanomaterial after fullerene and CNTs. G exhibits a high theoretical surface area of $2700 \mathrm{~m}^{2} / \mathrm{g}$ [38]. It possesses most of the advantages of CNTs. Moreover, it is prepared from graphite without any residual heterogeneous materials, which usually include residual metallic impurities and NPs derived from catalysts [25]. As a result, G is currently a popular option for SPSs.

Like G, GO is a monolayer of two-dimensional carbon-based materials containing multi-functional groups, such as carboxyl, epoxy, ketone and hydroxyl groups, in its basal and edge planes [39]. Due to its good water dispersibility, high mechanical strength and versatile surface modification, GO is now a popular alternative SPS in sample preparation.

\subsection{Metallic nanoparticles}

Metallic NPs, involving a wide range of different inorganic NPs, have unique properties, such as large specific surface area, high adsorption capacity and low temperature modification. Nowadays, metallic nanomaterials used as SPSs reportedly include $\mathrm{Fe}_{3} \mathrm{O}_{4}, \mathrm{TiO}_{2}, \mathrm{Al}_{2} \mathrm{O}_{3}$, $\mathrm{ZrO}_{2}, \mathrm{MnO}$, and $\mathrm{CeO}_{2}$, modified with functional coatings [40-47]. Among them, magnetic NPs (MNPs) are particularly useful for extracting and enriching a large volume of target analytes, because they can provide high surface area-to-volume ratio, easy surface modification and strong magnetism [48]. The extraction of magnetic nanomaterials with analytes is generally based on hydrophobic interaction, electrostatic attraction, and/or covalent-bonding formation. $\mathrm{Fe}_{3} \mathrm{O}_{4}$ nanomaterials are the most popular, and possess strong magnetism, so they are easily isolated from sample solutions by an external magnetic field without additional centrifugation and filtration $[48,49]$.

\subsection{Metal-organic frameworks}

MOFs are a new kind of hybrid inorganic-organic microporous crystalline material, self-assembled straightforwardly from metal ions with organic linkers via coordination bonds [50]. These materials have large surface areas in the range $1000-10400 \mathrm{~m}^{2} / \mathrm{g}$, tailorable polarity and pore size, and high thermal stability [51-53]. MOF materials have therefore attracted special attention in analytical applications.

In the past few years, MOFs emerged as a new class of porous hybrid material with great potential for applications in gas storage and separation [54]. Moreover, the promising MOFs, which offer a variety of topologies, porous networks, high surface areas, nanoscale porosity, tunable pore sizes, in-pore functions, and outsurface modification, have potential for the applications of catalysis [55], separation [54,56], gas storage [57] and drug delivery [58].

\section{Solid-phase sorbents for sample preparation prior to chromatographic analysis}

\subsection{Molecularly-imprinted polymers as solid-phase sorbents}

\subsubsection{Molecularly-imprinted solid-phase extraction}

Sample preparation using SPE was first introduced in the mid1970 s. As a classical sample-preparation method, SPE is still being used and developed, including off-line and on/in-line. Nevertheless, the major disadvantage of conventional SPE sorbents, such as $\mathrm{C}_{18}$, ion-exchange and size-exclusion phases, is the lack of selectivity, leading to co-extraction of matrix-interference components with the target analytes. MIPs have attracted great attention because they show promise as compound-selective or group-selective media. So, MIPs as SPE sorbents, have become a most important application area, which has been reviewed by Chen's group [5,18,59], by coupling with various chromatographic technologies, such as HPLC, GC and CE. MISPE has been applied using off-line, on-line and in-line modes.

3.1.1.1. Off-line molecularly-imprinted solid-phase extraction. Off-line MISPE involves loading the MIPs into SPE cartridges. The operational process is very similar to that for other SPE sorbents, including pre-conditioning, sample loading, washing and elution steps.

- Traditional MIPs. Table 1 summarizes MISPE applied in extracting analytes from environmental, biological and food samples [60-87]. It can be seen from Table 1 that more applications of MISPE are before HPLC than GC or CE in recent years. Besides the applications mentioned in Table 1, there are some other novel SPE applications using MIPs as SPSs prior to chromatography. For example, Peng et al. [88] used MIP-layer-coated silica NPs as the sorbents of dispersive SPE (dMISPE) for extracting trace sulfonylurea herbicides from soil and crop samples. The times of adsorption and desorption were $30 \mathrm{~min}$ and $20 \mathrm{~min}$, respectively. The performance was compared with commercial $\mathrm{C}_{18}$ sorbents, showing the binding capacity of the MIPs was much higher than that of $\mathrm{C}_{18}$. The dMISPEHPLC method exhibited high selectivity and sensitivity for the determination of sulfonylurea herbicides from spiked soil, rice, soybean, and corn samples.

Ebrahimzadeh et al. [89] combined dMISPE with dispersive liquidliquid microextraction (DLLME) for ultra-preconcentration and determination of mono-nitrotoluenes in wastewater samples using gas chromatography-flame ionization detector (GC-FID), where 3-nitrotoluene, MAA and EGDMA were template, functional monomer and cross-linker, respectively. Although the time of dMISPE was a little long (about $13 \mathrm{~h}$ ), the preconcentration factor of dMISPEDLLME was high ( 2800 under optimal conditions).

Lee et al. [90] used commercial MIPs and polypropylene flat sheet membrane to make a MIP micro-SPE (MI- $\mu$ SPE) device. Under optimal conditions of the MI- $\mathrm{SP}$ E-HPLC-fluorescence detector (FLD) method, ochratoxin A was selectively extracted and determined in roasted coffee samples.

Moreover, commercial MIPs materials can be purchased from different reagent companies. Also, MISPE cartridges purchased from these companies have exhibited excellent performance [91-93].

- Novel MIPs. Recently, magnetic SPE became a popular extraction mode of SPE based on the use of magnetic sorbents, when MIPs are grafted onto MNPs before MISPE.

Hiratsuka et al. [94] and Lin et al. [95] used magnetic MIPs as SPSs for the determination of estrogens in water samples. As the unique mechanical properties and extremely large surface area of MWCNTs, they can be an excellent candidate as the support material. Zhang et al. [96] used the MWCNTs as the support materials, and synthesized erythromycin-MIPs on the surface of MWCNTs according to surface imprinting technique. Under the optimized conditions, the erythromycin was purified and enriched from ethanol and chicken muscle by using the MWCNTs-MIPs, and the recoveries of erythromycin was in the range $85.3-95.8 \%$ in chicken muscle samples. Similarly, Gao et al. [97] also synthesized triclosan (TCS)MIPs based on CNTs coated with silica. The scheme of the synthetic route for CNTs@TCS-MIPs is shown in Fig. 2. The whole process via a multistep procedure is involved in the formation of TCSaminosilica monomer (APTES) complex, silica-shell deposition on the surface of CNTs, MIP-functionalized onto the silica surface and final extraction of TCS to generate the recognition sites. Then, 
Table 1

Selected applications of the technique of molecularly-imprinted polymer-solid-phase extraction (MIP-SPE)

\begin{tabular}{|c|c|c|c|c|c|c|c|}
\hline Template & Analyte & Matrix & Monomer/cross-linker & MIP synthesis & Analytical technique & LODs $(\mathrm{ng} / \mathrm{mL})$ & Ref. \\
\hline Thiabendazole & Thiabendazole & Citrus fruits & MAA/EDMA & $\begin{array}{l}\text { Grafted on porous } \\
\text { polyethylene frits }\end{array}$ & HPLC-FLD & $16^{\mathrm{a}}$ & [60] \\
\hline Quercetin & $\begin{array}{l}\text { Quercetin,quercetin-4'- } \\
\text { glucoside and quercetin-3,4'- } \\
\text { diglucoside }\end{array}$ & Yellow onion & 4-VP/EGDMA & Bulk & HPLC-UV & - & [61] \\
\hline Bromhexine & Bromhexine & Human serum and urine & MAA/EGDMA & Bulk & HPLC-UV & $0.1,0.3$ & [62] \\
\hline Oxytetracycline and Chlortetracycline & Tetracycline antibiotics & Lobster, milk and honey & MAA/TRIM & Precipitation polymerization & HPLC-UV & - & [63] \\
\hline Rutin & Rutin & S. chinensis & $\begin{array}{l}\mathrm{AA} \text { and } 2-\mathrm{VP} / \mathrm{EGDMA} \\
\text { and DVB }\end{array}$ & Bulk & HPLC-UV & 6.7 & [64] \\
\hline Quercetin & Catechins & Red, white, green and black tea & 4-VP/EGDMA & Bulk & HPLC-UV & - & [65] \\
\hline Quercetin & Rutin and quercetin & Cacumen platycladi & AA/EGDMA & Bulk & HPLC-UV & - & [66] \\
\hline Amiodarone & Amiodarone & Blood serum & 4-VP/EGDMA & Bulk & HPLC-UV & 20 & [67] \\
\hline Metolachlor deschloro & Chloroacetamide herbicides & Food samples & MAA/EGDMA & Suspension polymerization & HPLC-MS/MS & $0.1-0.5^{\mathrm{a}}$ & [68] \\
\hline Trichothecene-2 & Trichothecenes & Maize, barley and oat samples & MAA/EGDMA & Radical polymerization & HPLC-MS/MS & $0.3-2.3^{\mathrm{a}}$ & [69] \\
\hline Oxytetracycline hydrochloride & Oxytetracycline residues & Milk & MAA/TEOS & Sol-gel technology & HPLC-UV & $4.8-12.7^{\mathrm{a}}$ & [70] \\
\hline Citalopram & Citalopram & Human serum and urine & MAA/EGDMA & Bulk & HPLC-UV & 0.4 & [71] \\
\hline Imidazole & Imidazole & Water samples & MAA/EDMA & grafted on silica & HPLC-UV & - & [72] \\
\hline 3-methylflavone-8-carboxylic acid & $\begin{array}{l}\text { 3-methylflavone-8-carboxylic } \\
\text { acid }\end{array}$ & human urine & MAA/EGDMA & Bulk & ZHILC-UV & - & [73] \\
\hline BPA & $\mathrm{BPA}$ & Water samples & APTES/TEOS & Grafted on silica & HPLC-UV & 2 & [74] \\
\hline Diphenolic Acid & Diphenolic Acid & & & & & & \\
\hline Propyl gallate & Antiplatelet active ingredients & Radix Salviae Miltiorrhizae & 4-VP/EGDMA & Bulk & HPLC-MS/MS & - & [75] \\
\hline Sudan I & Sudan I & Chili Sauce Samples & MAA/DVB & $\begin{array}{l}\text { Multistep seed swelling } \\
\text { polymerization }\end{array}$ & HPLC-UV & $3.3,5.0^{\mathrm{a}}$ & [76] \\
\hline Atrazine & Atrazine & Lettuce and corn samples & MAA/EGDMA & Precipitation polymerization & HPLC-UV & - & [77] \\
\hline Atrazine & Triazines & Soil & MAA/DVB & $\begin{array}{l}\text { Two-step swelling } \\
\text { polymerization }\end{array}$ & HPLC-UV & $2.8-9.6$ & [78] \\
\hline Deltamethrin or cypermethrin & Pyrethroid insecticides & Aquaculture seawater & MAA/EGDMA & Bulk & GC-ECD & $0.017-0.68$ & [79] \\
\hline Methanidophos & Methanidophos & Surface water and soil & MAA/EGDMA & Bulk & GC-NPD & $3.8^{\mathrm{a}}, 0.010,0.013$ & [80] \\
\hline 16 PAHs & 16 PAHs & Seawater & PTMS/TEOS & Grafted on silica & GC-MS & $0.052-0.126$ & [81] \\
\hline $\begin{array}{l}\text { 4,4'-(hexafluoroisopropylidene)- } \\
\text { diphenol }\end{array}$ & $\mathrm{BPA}$ & Water & 4-VP/ TRIM & Bulk & GC-MS & $10^{-5}$ & [82] \\
\hline Diisononyl phthalate & Phthalates esters & $\begin{array}{l}\text { Plastic bottled beverage } \\
\text { products }\end{array}$ & $\mathrm{AM} / \mathrm{DVB}$ & Precipitation polymerization & GC-FID & $0.85-1.38$ & [83] \\
\hline PAHs & PAHs & Air dust & 4-VP/EGDMA & Bulk & GC-MS & $1.5 \times 10^{-4}$ & [84] \\
\hline TMB & Polybrominated biphenyls & Water and fish & $\gamma$-MPTMS/TMOS & Grafted on silica & GC-ECD & $0.002-0.008$ & [85] \\
\hline BPA & BPA & - & MAA/EGDMA & Bulk & CE-UV & 100 & [86] \\
\hline $\mathrm{BPA}$ & EDCs & $\begin{array}{l}\text { Tap, waste, river and shrimp } \\
\text { water }\end{array}$ & 4 -VP/TRIM & precipitation polymerization & CE-UV & $1.8-84$ & [87] \\
\hline
\end{tabular}

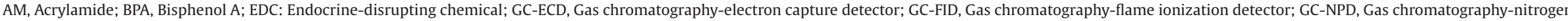

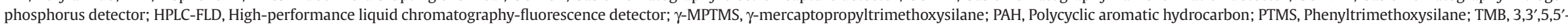
tetramethylbenzidine; TEOS, Tetraethoxysilane; TMOS, Tetramethoxysilane; TRIM, Trimethylolpropane trimethylacrylate; ZHILC, Zwitterionic hydrophilic interaction liquid chromatography.

a ng/g. 


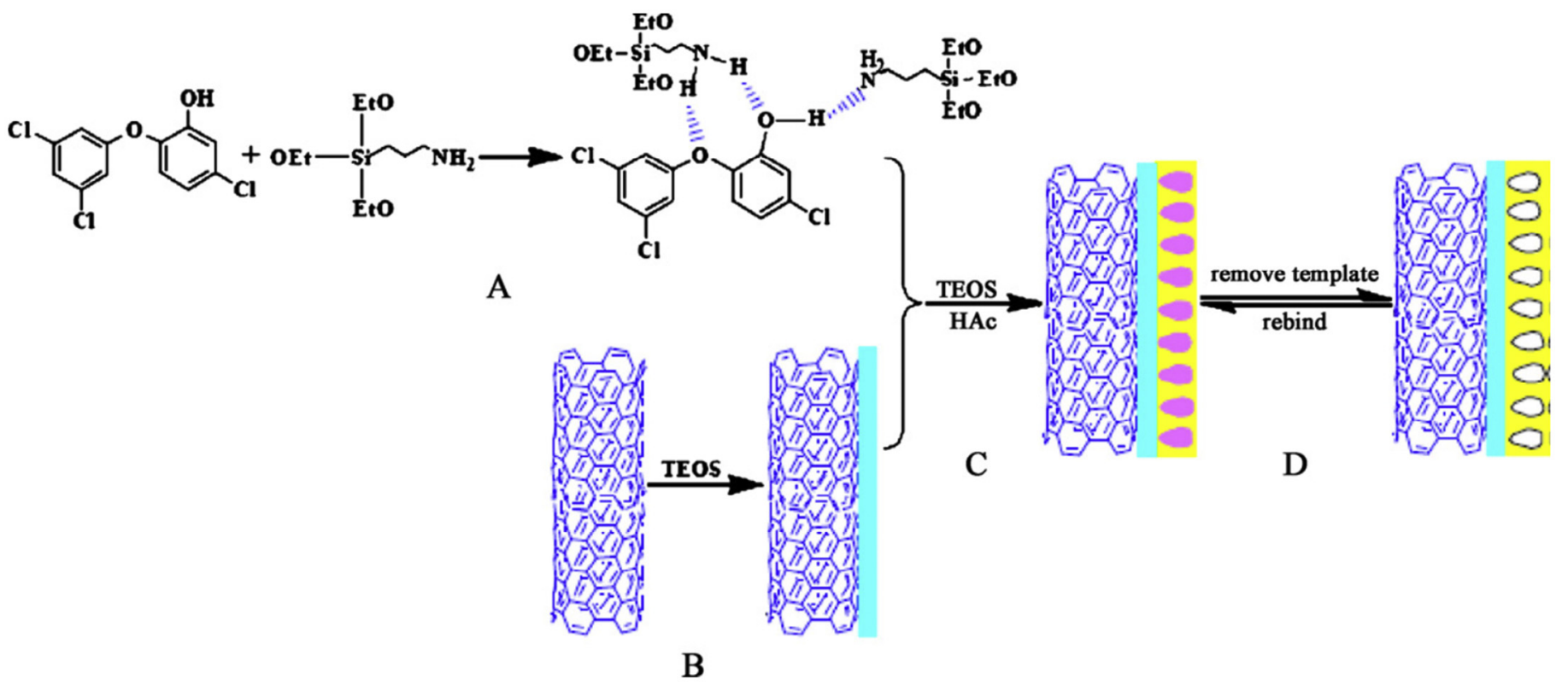

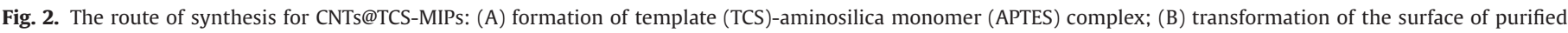

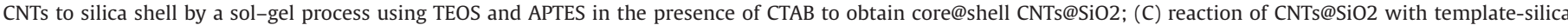

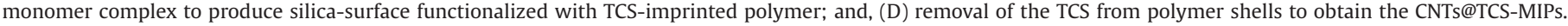
(Reprinted with permission from [97]. (C) 2011 Elsevier).

CNTs@TCS-MIPs were used as the sorbents of dMISPE for the extraction of TCS in river-water and lake-water samples prior to HPLC. This method combined the merits of surface molecular imprinting and CNTs. The polymers showed fast kinetics, high capacity and favorable selectivity.

3.1.1.2. On-line molecularly-imprinted solid-phase extraction. In this format, a small SPE column packed with MIPs is usually placed in a six-port valve loop of HPLC. After the sample loading and washing out interfering compounds (the analytes are preconcentrated by the MISPE column), the analytes are eluted by the HPLC mobile phase [98-104]. These research works mainly focused on the analytes of Sudan dyes [98], Para Red [99], riboflavin [100], fluoroquinolone antimicrobials [101], tetracycline antibiotic residues [102], triazine residues [103] and estrogens [104] in samples from the environment (e.g., water and soil) and food (e.g., tomato sauce, chili sauce, egg, and milk).

Guo et al. [105] synthesized chlorsulfuron-MIPs by using vinylimidazolium ionic liquid as functional monomer. MIPs were also used as the on-line SPE-HPLC sorbents for the determination of chlorsulfuron in samples of reservoir water, pond water, detergent and tap water. The low limit of detection (LOD) and high recoveries showed that novel MIPs sorbents were excellent SPSs for the extraction of chlorsulfuron.

Like off-line MISPE, there are also some applications of MWCNTsMIPs in the on-line MISPE mode. For example, MWCNTs-MIPs online SPE was developed for the determination of trace Sudan IV in chili-powder samples [106].

3.1.1.3. In-line molecularly-imprinted solid-phase extraction. Extraction, enrichment, separation and determination of target analytes can be achieved in one single step by the direct coupling of a MIP column in-line with the detection system, thanks to the high selectivity provided by MIPs. Also, the column of in-line MISPE is usually called an MI-monolithic column.

The first in-line MISPE was described by Sellergren for the determination of pentamidine in urine [107]. And the first evaluation of MIPs as in-line concentrator in CE was reported by Lara et al. [108].

Zhang et al. [109] demonstrated a novel light-emitting diodeinduced polymerization technology that could be applied as an incolumn MISPE concentrator in CE. The constructed concentrator exhibited good selectivity, high extraction efficiency, and little sacrifice of CE separation efficiency for the analytes, epitestosterone, methyltestosterone, and testosterone acetate.

Zheng et al. [110] reviewed the developments and the applications of the MI-monolithic column for HPLC and CE. The combination of monolithic column and MIPs integrated the high separation efficiency of modern chromatography and the high selectivity of MIPs.

Canale et al. [82] packed BPA-MIPs into monolithic column and installed it on an HPLC unit for the determination of BPA in realworld water samples. The monolithic column exhibited good selectivity and concentration capability in the analysis of BPA in water samples.

\subsubsection{Solid-phase microextraction, matrix solid-phase dispersion and stir-bar sorptive extraction}

Because MIPs present several advantages in terms of mechanical robustness, resistance to elevated temperatures and pressures, inertness to extreme pHs, easier and cheaper preparations, especially for their high selectivity for the target analytes, MIP materials are now becoming very popular in SPME, MSPD and SBSE methods. The combination of molecular imprinting and these three extraction methods would therefore ideally provide powerful analytical tools with the characteristics of simplicity, flexibility, and selectivity. The principles of the three extraction methods have been described in detail [59], and here we do not describe them again.

Table 2 summarizes some new applications of MIPs as SPSs in the three extraction methods. For SPME, the MIPs are usually coated on a fiber segment, and then the fiber is inserted into the SPME device for the extraction [111-126]. Sometimes, nanomaterials can 
Table 2

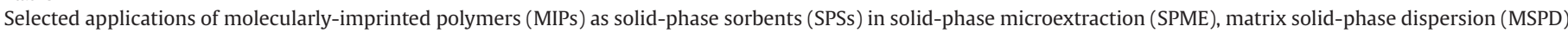
and stir-bar sorptive extraction (SBSE)

\begin{tabular}{|c|c|c|c|c|c|c|}
\hline Template & Analyte & Matrix & Application methods & Analytical technique & $\mathrm{LOD}(\mathrm{ng} / \mathrm{mL})$ & Ref. \\
\hline $17 \beta$-estradiol & Estrogens & Fish and shrimp tissue samples & SPME & HPLC-UV & $0.98-2.39$ & [111] \\
\hline Chlorogenic acid & Chlorogenic acid & Echinacea purpurea & SPME & HPLC-UV & 0.08 & [112] \\
\hline Caffeine & Caffeine & Human serum & SPME & GC-MS & 0.1 & [113] \\
\hline Ametryn & Triazines & Onion, maize and rice seeds & SPME & GC-FID & $9-85$ & [114] \\
\hline Sudan I & Sudan I-IV dyes & $\begin{array}{l}\text { Hot chili powder and poultry } \\
\text { feed }\end{array}$ & SPME & HPLC-UV & $2.5-4.6^{\mathrm{a}}$ & [115] \\
\hline Ephedrine & $\begin{array}{l}\text { Ephedrine and } \\
\text { pseudoephedrine }\end{array}$ & Human urine and serum & $\begin{array}{l}\text { SPME } \\
\text { (monolithic column) }\end{array}$ & CE-UV & $0.96-200$ & [116] \\
\hline Prometryn & Triazines & $\begin{array}{l}\text { River water, wastewater and } \\
\text { liquid milk }\end{array}$ & SPME & HPLC-UV & $0.08-0.38$ & [117] \\
\hline Testosterone & Anabolic steroids & Water and urine samples & SPME & GC-MS & $0.008-0.020$ & [118] \\
\hline 17ß-estradiol & EDCs & River water & SPME & GC-MS & $0.0013-0.022$ & [119] \\
\hline Thiamphenicol & Thiamphenicol & Milk and honey & SPME & HPLC-UV & $3,2^{\mathrm{a}}$ & [120] \\
\hline Thiabendazole & Thiabendazole & Orange juice & SPME & HPLC-FLD & 4 & [121] \\
\hline Ciprofloxacin & $\begin{array}{l}\text { Fluoroquinolone } \\
\text { antibiotics }\end{array}$ & Water & SPME & HPLC-MS/MS & $0.0008-0.0081$ & [122] \\
\hline$\alpha, \alpha^{\prime}$-Azobis(isobutyronitrile) & Quinolones & Serum & MSPD & HPLC-UV & $40-90^{\mathrm{a}}$ & [123] \\
\hline Atrazine & Triazines & Soil, fruit and vegetable & MSPD & CE-UV & $12.9-31.5^{\mathrm{a}}$ & [124] \\
\hline Terbuthylazine & Triazines & Rice, apple, lettuce and soil & SBSE & HPLC-UV & $0.04-0.12$ & [125] \\
\hline Triadimefon & Triazole fungicides & Soil & SBSE & HPLC-UV & $0.14-0.34$ & [126] \\
\hline
\end{tabular}

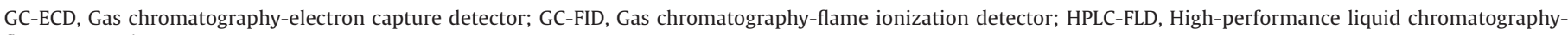
fluorescence detector.

a $\mathrm{ng} / \mathrm{g}$.

be combined with MIPs in order to modify the extraction efficiency $\{$ e.g., CNTs $[112,117]\}$.

Golsefidi et al. [112] reported that MWCNTs were added into the MIP solutions gradually to form a dispersed mixture. After that, $12 \mu \mathrm{L}$ of the dispersed mixture was injected into a $2.5-\mathrm{cm}$ long polypropylene hollow-fiber segment. Then, the MWCNTs-MIPs fiber was submerged in the sample solution and completed the extraction process [112].

Different from that, prometryn MWCNTs-MIPs were prepared by copolymerization of MAA and TRIM in the presence of prometryn on the surface of modified-MWCNTs [117]. This means the MWCNTs were used as support materials of MIPs. Then the MWCNTs-MIPs were introduced on a segment of polypropylene. After heatsealing the two ends of the fiber, it was clamped onto a paper clip for microextraction [117].

Moreover, some metallic materials are used as support materials for MIPs. For example, an SPME fiber was fabricated through ultraviolet irradiation polymerization of ametryn-MIPs on the surface of anodized-silylated aluminum wire [114]. In order to investigate the extraction mechanism, four fibers were used for comparison, including cleaned aluminum wire, anodized aluminum wire, anodized and silylated aluminum wire, and anodized and silylated aluminum wire coated with a MIP layer. The chromatograms of extracted ametryn (Fig. 3 ) revealed that the extraction ability of the anodized-silylated aluminum-wire fiber was definitely higher than that of the other fibers.

Besides the SPME fiber, MIPs can be prepared by an in-situ polymerization method to form a MIP micro-monolithic column [116]. The polymerization mixture, consisting of template, functional monomer, cross-linker and initiator, was filled into a $30 \mathrm{~cm} \times 530 \mu \mathrm{m}$ capillary. The two ends of capillary were sealed with rubbers, then the capillary was placed in a water bath at $60^{\circ} \mathrm{C}$ to react for $24 \mathrm{~h}$. After polymerization, the capillary was cut into $5-\mathrm{cm}$ pieces. Then $1-\mathrm{cm}$ silica wall at one end of the capillary was broken and peeled off mechanically with a blade. The cut portion of 1-cm MIP fiber was used for SPME. Finally, the capillary pieces were immersed in a solution to remove the template compound. Fig. 4 shows the whole implementation process of the micro-monolithic column. The fabricated MIP monolithic column can be immersed in the sample solution for microextraction. And, after solution desorption, the analytes can be determined by $\mathrm{CE}$.

\subsection{Carbon nanomaterials as solid-phase sorbents}

Because of their large adsorption surface area-to-volume ratios and high affinity, good physical and chemical stability, and low cost, carbon nanomaterials are increasingly popular as SPSs in sample preparation prior to chromatography. CNTs and G/GO are the most widely used SPSs in extraction methods, including SPE, SPME, MSPD and SBSE. Table 3 summarizes recent popular applications of carbon nanomaterials used as SPSs in sample preparation prior to chromatography $[23,25,31,127-173]$.

\subsubsection{Carbon nanotubes}

As seen from Table 3, MWCNTs, magnetic MWCNTs, functionalized MWCNTs and SWCNTs are used as the sorbents for SPE, SPME and MSPD. CNTs in sample preparation have been reviewed in detail by Zhang et al. [32]. Using magnetic MWCNTs as SPE sorbents can avoid tedious steps, such as centrifugation and filtration [135-138]. And self-assembled poly(diallyldimethylammonium chloride) (PDDA)-functionalized MWCNTs were used as anion-exchange sorbents for extraction of acidic degradation products of nerve agents [139].

By comparison with commercial strong anion-exchange and MAX, PDDA-MWCNTs presented superior recoveries, which may be attributed to the combined effects of the high charge density of the polyelectrolyte plus the highly hydrophobic CNT surface. Because at neutral $\mathrm{pH}$, analytes exist as anions, they are expected to be retained on the cationic surface of PDDA-MWCNT composite via primary electrostatic interactions. However, secondary hydrophobic interactions between alkyl groups of analytes and the CNT surface also facilitate their retention. This means that there were two interactions between the analytes and the PDDA-MWCNT materials, so high charge density of polyelectrolyte plus the highly hydrophobic CNT surface may lead to high extraction recovery [139].

For dSPE and $\mu$ SPE technologies, MWCNTs can be an excellent material for a quick, easy, cheap, effective, rugged and safe (QuEChERS) method. Zhao et al. [131] used MWCNTs as a reverse 


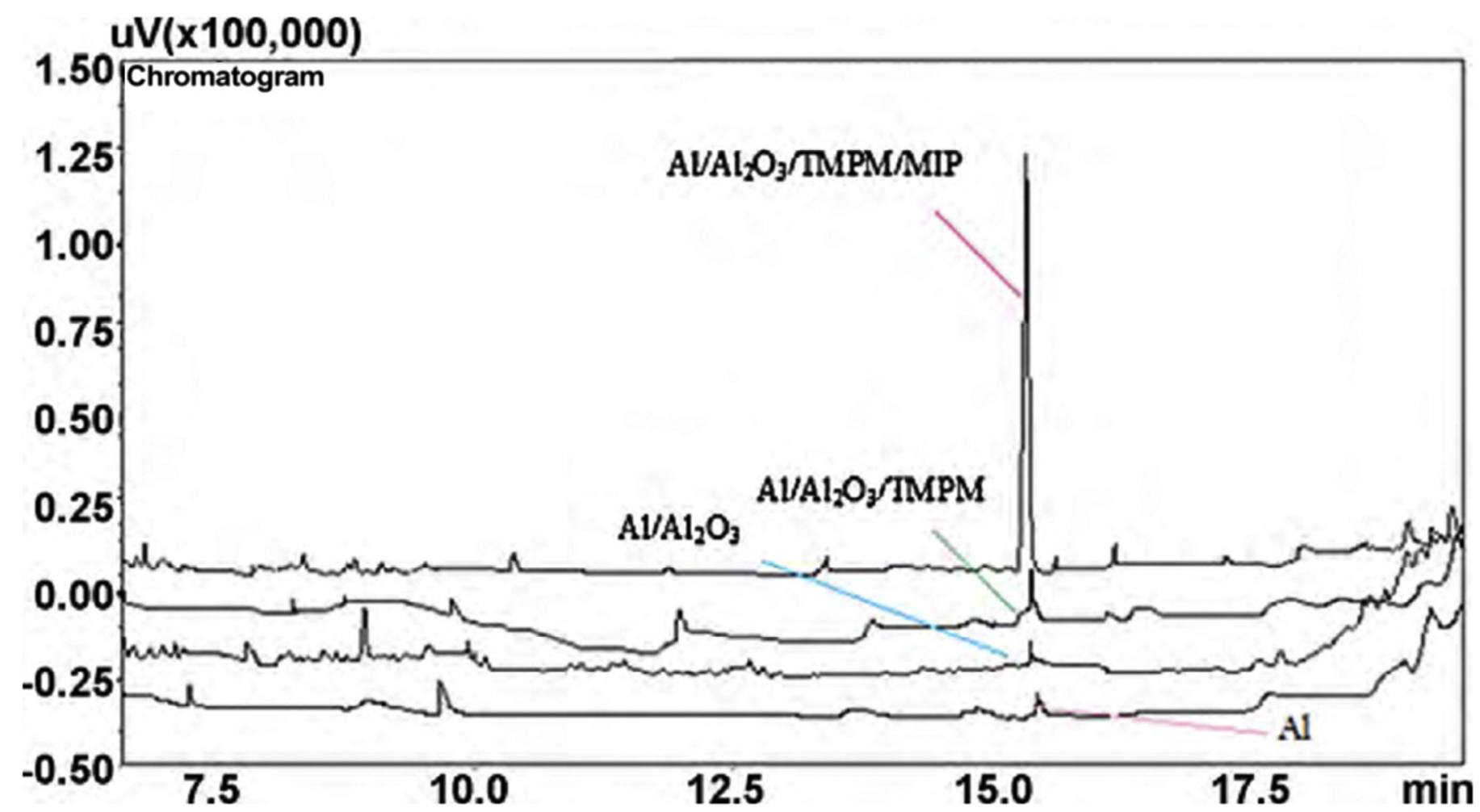

Fig. 3. Chromatography results of SPME procedure by different fibers. (Reprinted with permission from Ref [114]. ( 2010 Elsevier).

dSPE material combining with GC-MS for the determination of 14 pesticides in leek, onion, ginger and garlic samples. The recoveries of the target analytes in the complex matrices at two concentration levels $(0.02 \mathrm{mg} / \mathrm{kg}$ and $0.2 \mathrm{mg} / \mathrm{kg}$ ) were $78-110 \%$. The LODs for the analytes were $1-6 \mu \mathrm{g} / \mathrm{kg}$. In the $\mu$ SPE device, MWCNTs were employed as sorbents and were packed inside a porous polypropylene membrane "envelope", whose edges were heat-sealed to secure the contents. The $\mu$ SPE device was placed in a stirred sample solution to extract the analytes [134]. Wu et al. [134] used two micropipette tips to make an MWCNT-packed micro-column, followed by flow-injection SPE. Good linearity, reproducibility and LOD were obtained.
Although CNTs enjoy excellent properties, due to their rigidity, chemical inertness and self-aggregation with strong van der Waals forces, they are difficult to dissolve or to disperse in common organic solvents or polymeric matrices, which makes CNTs unsuitable as SPSs of SPME. Great efforts have been made to functionalize CNTs to improve their solubility. Sarafraz-Yazdi's group has investigated poly(ethylene glycol) (PEG)-grafted MWCNTs as sorbents of SPME [140-143]. The -COOH-functionalized group-grafted MWCNTs enhanced their dispersion and compatibility [144,145].

Self-assembly amino-functionalized MWCNTs (MWCNTs- $\mathrm{NH}_{2}$ ) were anchored to the stainless-steel wire as SPSs for the SPME of phenols compounds by Feng et al. [146]. Results showed that the

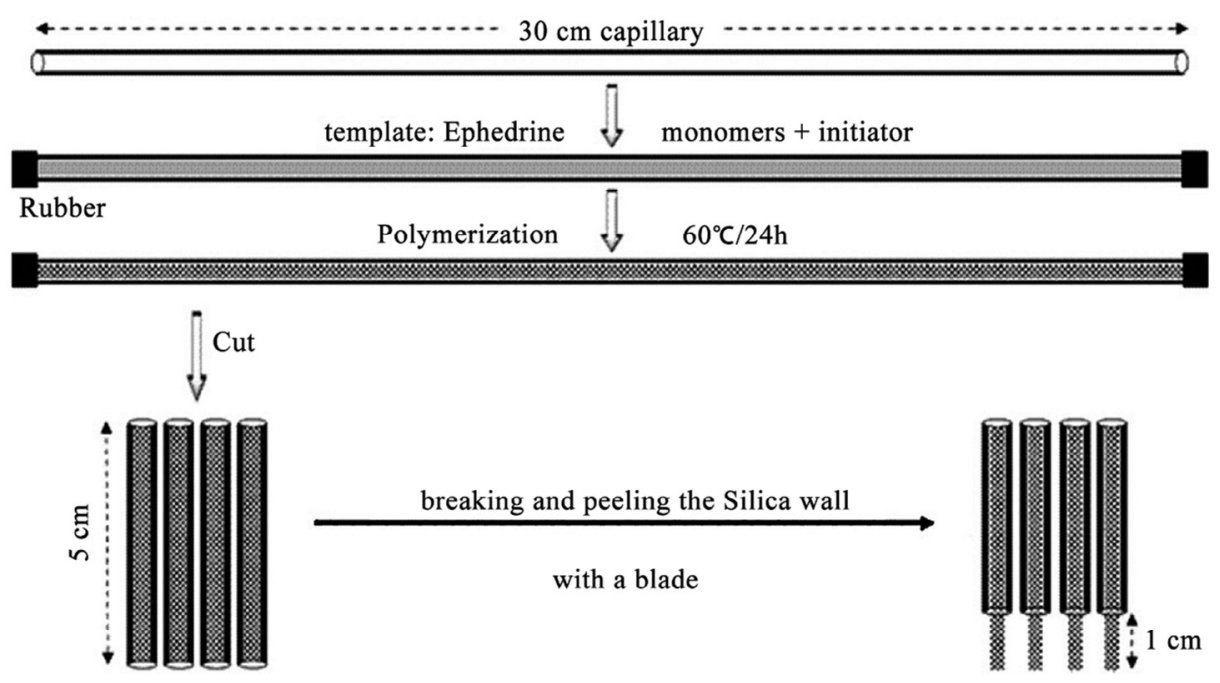

Fig. 4. MIP micro-monolithic column-preparation procedure. (Reprinted with permission from [116]. () 2010 Elsevier). 
Table 3

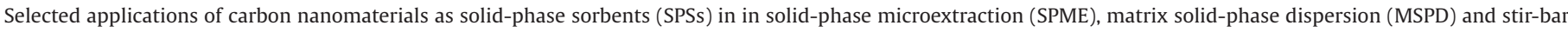
sorptive extraction (SBSE)

\begin{tabular}{|c|c|c|c|c|c|c|}
\hline Carbon nanomaterials & Analyte & Matrix & $\begin{array}{l}\text { Application } \\
\text { methods }\end{array}$ & $\begin{array}{l}\text { Analytical } \\
\text { technique }\end{array}$ & LOD (ng/mL) & Ref. \\
\hline \multirow[t]{9}{*}{ MWCNTs } & BPA etc. & Tap, river, waste water & SPE & HPLC-FLD & $0.018-0.083$ & [31] \\
\hline & $\begin{array}{l}\text { Metsulfuron methyl and } \\
\text { chlorsulfuron }\end{array}$ & $\begin{array}{l}\text { Lake, creek, reservoir and } \\
\text { underground water }\end{array}$ & SPE & CE-UV & $0.40,0.36$ & [127] \\
\hline & Marine DOM & Sea water & SPE & SEC-UV & - & [128] \\
\hline & 16 PAHs & Tap, river, sea water & SPE & GC-MS & $0.002-0.0085$ & [129] \\
\hline & Organophosphorus pesticides & Peanut oil & dSPE & GC-MS & $0.7-1.6^{\mathrm{a}}$ & [130] \\
\hline & 14 pesticides & leek, onion, ginger and garlic & dSPE & GC-MS & $2-20^{\mathrm{a}}$ & [131] \\
\hline & Quinolone antibiotics & Mineral, tap, waste water & dSPE & CE-UV & $0.028-0.094$ & [132] \\
\hline & $16 \mathrm{PAHs}$ & River water & $\mu \mathrm{SPE}$ & GC-MS & $0.0042-0.0465$ & [133] \\
\hline & 16 PAHs & River water & $\mu$ column SPE & GC-MS & $0.001-0.15$ & [134] \\
\hline \multirow[t]{4}{*}{ Magnetic MWCNTs } & $\mathrm{BPA}$ and $\mathrm{BPF}$ & Tap, river, snow water & MSPE & GC-MS/MS & $0.001-0.06$ & [135] \\
\hline & Phthalate acid esters & Beverage and perfume & MSPE & GC-MS & $0.0049-0.038$ & [136] \\
\hline & Estrogens & $\begin{array}{l}\text { Tap, mineral, Pearl River water } \\
\text { and honey }\end{array}$ & MSPE & CE-UV & $0.1-0.2$ & [137] \\
\hline & Aconitines & Human serum & MSPE & HPLC-UV & $3.1-4.1$ & [138] \\
\hline PDDA grafted MWCNTs & $\begin{array}{l}\text { Degradation products of nerve } \\
\text { agents }\end{array}$ & Water & SPE & GC-MS & $0.11-0.25$ & [139] \\
\hline \multirow[t]{4}{*}{ PEG grafted MWCNTs } & BTEX & $\begin{array}{l}\text { Tap, mineral, waste and well } \\
\text { water }\end{array}$ & SPME & GC-FID & $0.0006-0.003$ & [140] \\
\hline & PAHs & Saffron & SPME & GC-FID & $0.001-0.05$ & [141] \\
\hline & Furan & $\begin{array}{l}\text { Apple and orange juice, } \\
\text { banana/wheat/milk and fruit/ } \\
\text { wheat/milk }\end{array}$ & SPME & GC-FID & $0.00025,0.001$ & [142] \\
\hline & $\begin{array}{l}\text { Non-steroidal anti- } \\
\text { inflammatory drugs }\end{array}$ & Tap, river, waste and well water & SPME & GC-FID & $0.007-0.03$ & [143] \\
\hline -COOH grafted MWCNTs & Phenobarbital & Clinical wastewater & SPME & HPLC-UV & 0.32 & [144] \\
\hline MWCNTs bonded on Au wires & Diazinon and fenthion & $\begin{array}{l}\text { Ground, surface, lagoons and } \\
\text { drinking water }\end{array}$ & SPME & GC-FID & $0.2,0.3$ & [145] \\
\hline $\begin{array}{l}\text { MWCNTs bonded on stainless } \\
\text { steel wire }\end{array}$ & Phenols compounds & River water & SPME & GC-FID & $0.01-0.02$ & [146] \\
\hline SWCNTs & EDCs & Tap and sea water & On-line SPME & HPLC-UV & $0.32-0.52$ & [147] \\
\hline \multirow[t]{2}{*}{ MWCNTs } & Hormones & Butter & MSPD & GC-MS & $0.2-1.3^{\mathrm{a}}$ & [148] \\
\hline & 9 Organophosphorus Pesticides & Fruit and vegetables & MSPD & LC-MS-MS & $0.06-0.15^{\mathrm{a}}$ & [149] \\
\hline \multirow[t]{2}{*}{ G } & Chlorophenols & Tap and river water & SPE & HPLC-UV & $0.1-0.4$ & [151] \\
\hline & Neurotransmitters & Rat brain & SPE & HPLC-FLD & $23.4-67.5^{\mathrm{a}}$ & [152] \\
\hline \multirow[t]{6}{*}{$\mathrm{G}-\mathrm{Fe}_{3} \mathrm{O}_{4} \mathrm{MNPs}$} & Triazine herbicides & Reservoir, lake and river water & MSPE & HPLC-UV & $0.025-0.040$ & [153] \\
\hline & Neonicotinoid insecticides & Reservoir, sea and river water & MSPE & HPLC-UV & $0.004-0.01$ & [154] \\
\hline & Phthalate esters & $\begin{array}{l}\text { Bottled and river, Cola and } \\
\text { green tea }\end{array}$ & MSPE & HPLC-UV & $0.01-0.04$ & [155] \\
\hline & Carbamate pesticides & River, pool and reservoir water & MSPE & HPLC-UV & $0.02-0.04$ & [156] \\
\hline & PAHs & Soil & $\mu \mathrm{SPE}$ & GC-MS & $0.0017-0.0057^{a}$ & [157] \\
\hline & PAHs & River water & $\mu \mathrm{SPE}$ & GC-MS & $0.0008-0.0039$ & [158] \\
\hline \multirow[t]{7}{*}{ G } & Carbamates & Sea, lake and tap water & SPME & HPLC-UV & $0.1-0.8$ & [159] \\
\hline & $\begin{array}{l}\text { Polybrominated diphenyl } \\
\text { ethers }\end{array}$ & Canal water & SPME & GC-MS & $0.0002-0.0053$ & [160] \\
\hline & Triazine herbicides & Tap, sea and lake water & SPME & HPLC-UV & $0.05-0.2$ & [161] \\
\hline & Organochlorine pesticides & River water & SPME & GC-ECD & $0.00016-0.00093$ & [162] \\
\hline & Pyrethroid pesticides & Pond water & SPME & GC-ECD & $0.00369-0.00694$ & [163] \\
\hline & PAHs & River and pond water & SPME & GC-MS & $0.00152-0.00272$ & [25] \\
\hline & Phenols & Pond water & SPME & GC-FID & $0.34-3.4$ & [164] \\
\hline GO & PAHs & River water & SPME & GC-FID & $0.005-0.08$ & [165] \\
\hline \multirow[t]{2}{*}{ G } & $16 \mathrm{PAHs}$ & Tap and lake water & SBSE & GC-MS & $0.005-0.429$ & [166] \\
\hline & $\begin{array}{l}\text { Polybrominated diphenyl } \\
\text { ethers }\end{array}$ & Soil and fishes & MSPD & GC-ECD & $0.0053-0.2126^{\mathrm{a}}$ & [167] \\
\hline Nanohorns & PAHs & River, tap and bottled water & $\mu \mathrm{SPE}$ & GC-MS/MS & $0.03-0.06$ & {$[168]$} \\
\hline Nanohorns & Triazines & River, tap and bottled water & $\mu \mathrm{SPE}$ & GC-MS & $0.015-0.1$ & [169] \\
\hline Nanocones/disks & Chlorophenols & $\begin{array}{l}\text { Drinking, swimming pool, } \\
\text { water-tank and well water }\end{array}$ & SPE & GC-MS & $0.3-8$ & [23] \\
\hline Nanocones/disks & Toluene etc. & Drinking, well and river water & SPME & GC-MS & $0.15-2$ & [170] \\
\hline Nanofiber & $\begin{array}{l}\text { Chlorotriazines and } \\
\text { dealkylated metabolites }\end{array}$ & $\begin{array}{l}\text { Ground, creek, tap water and } \\
\text { soil }\end{array}$ & $\mu \mathrm{SPE}$ & HPLC-UV & $0.004-0.03$ & [171] \\
\hline Nanofiber & Aromatic amines & Wastewaters & $\mu \mathrm{SPE}$ & HPLC-UV & $0.009-0.081$ & [172] \\
\hline Nanofiber & Benzene etc. & & SPME & GC-FID & $0.01-0.08$ & [173] \\
\hline
\end{tabular}

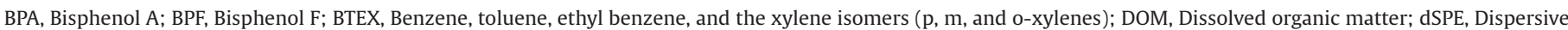

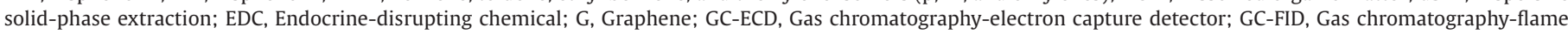

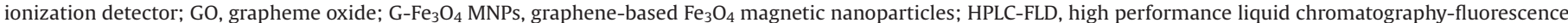

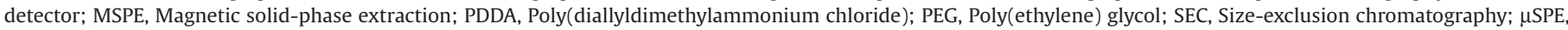
Micro-solid-phase extraction.

a ng/g. 
fabricated MWCNT fiber had higher extraction efficiency than the commercially available fibers.

SWCNTs can also exhibit good extraction efficiency. For example, SWCNT fibers for SPME were prepared using the electrophoretic deposition method [147]. The fibers were immersed into sample solutions for extraction of endocrine-disrupting chemicals (EDCs). After that, the fiber was inserted into the desorption chamber of the interface. The desorbed analytes were delivered into the HPLC column by the mobile phase when the valve was switched from the load to the injection position.

Table 3 lists the applications of MWCNTs-MSPD [148,149]. For MSPD and SBSE, there are a few research works about CNTs as SPSs and further explorations are essential in future sample-preparation development.

\subsubsection{Graphene, graphene oxide and other carbon nanomaterials}

Sitko et al. reviewed the adsorptive properties of G and GO and their applications in preconcentrating organic compounds and tracemetal ions by SPE, SPME and magnetic SPE methods, including trace analysis of water, food, biological and environmental samples using chromatography and spectroscopy techniques [150]. Table 3 summarizes G/GO as SPSs used in SPE, SPME, MSPD and SBSE [25,151-167].

Like CNTs, there are also a lot of research works about G $[151,152,159-162,166,167]$ and magnetic $G$ [146-149] grafted onto the stainless steel fiber [162,163], functional G \{e.g., polypyrrole/ graphene composite-coated fiber [164] \} and GO [165] used for SPSs. Usually, G-NPs are derived from deoxidized GO-NPs. For example, Zhang et al. prepared a G-coated SPME fiber following deoxidization of GO-NPs [25]. The whole fabrication included five processes (Fig. 5). The surface of the $\mathrm{SiO}_{2}$ substrate was first modified by the amino group according to silanization reaction, and was then inserted into the GO dispersion solution to complete the GO modification. Finally, the fiber was deoxidized to give the G-coated SPME fiber. The fabricated G-coated fiber was exposed to the headspace above water solutions for extraction of polycyclic aromatic hydrocarbons (PAHs) followed by GC-MS determination. Under the optimized extraction and determination conditions, the LODs of eight PAHs were $1.52-2.72 \mathrm{ng} / \mathrm{L}$ and recoveries were $72.7-101.7 \%$ for samples of river water, pond water and soil.

Table 3 also lists the applications of other carbon nanomaterials, such as nanohorns, nanocones, nanodisks and nanofibers, as SPSs [23,168-173]. All the nanomaterials exhibited excellent extraction efficiencies in SPE, SPME, MSPD and SBSE.

\subsection{Metallic nanoparticles as solid-phase sorbents}

\subsection{1. $\mathrm{Fe}_{3} \mathrm{O}_{4}$ magnetic nanoparticles}

As mentioned above, MNPs are particularly useful for extracting and enriching a large volume of target analytes because they provide a large surface area-to-volume ratio, easy surface modification and strong magnetism. The MNPs can therefore be quickly isolated from matrix solutions using an external magnet after extraction and have excellent extraction efficiencies. Conventional SPE needs the sorbent to be packed into the column and time-consuming loading of large-volume samples, while the magnetic extraction method is not only convenient, economical and highly efficient, but also overcomes the above problems. However, pure iron-oxide NPs can easily form large aggregates, which may alter their magnetic properties. Moreover, these nm-sized metal oxides are not target selective and are unsuitable SPSs for samples with complicated matrices. A suitable coating is therefore essential to overcome such limitations. Chen et al. [174] reviewed the applications of magnetic materials, combined with other materials (e.g., silica, $\mathrm{C}_{18}$, polymers and surfactants), for the separation and the preconcentration of pollutants in water samples.
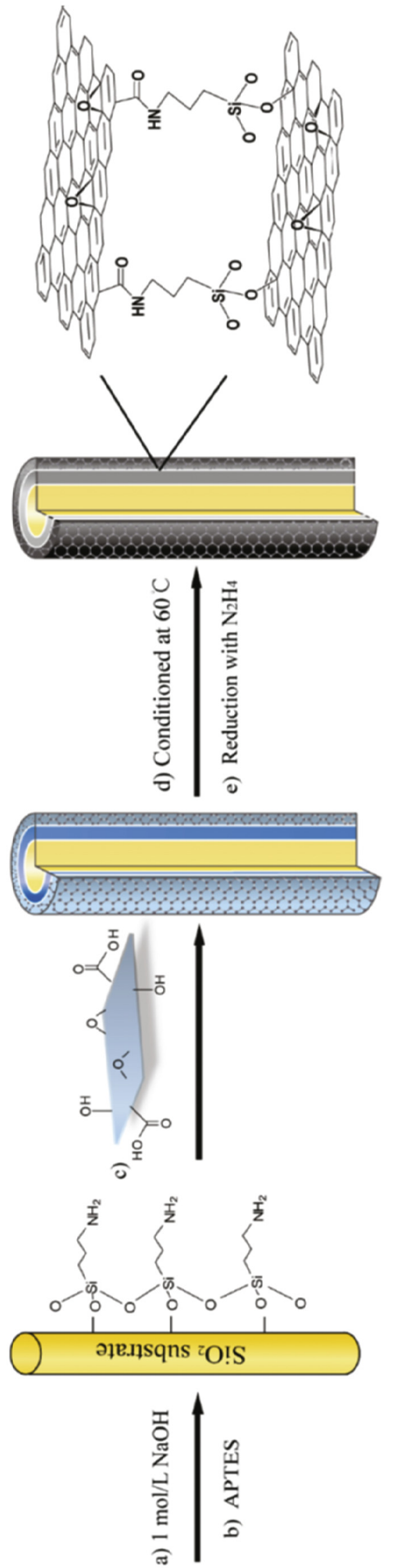

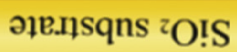

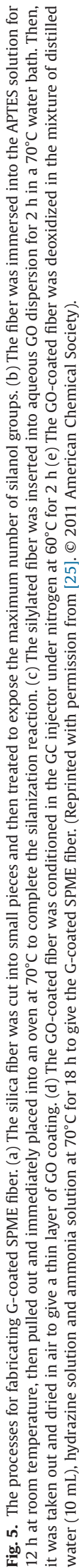


In recent years, there were also some novel applications of $\mathrm{Fe}_{3} \mathrm{O}_{4}$ NPs functionalized with:

- $\mathrm{Al}_{2} \mathrm{O}_{3}$ for the extraction of alendronate in human urine samples [175] and glyphosate and aminomethylphosphonic acid in water and guava-fruit extract [176];

- carbon for the extraction of BPA and PAHs in water samples [177,178]; and,

- $\mathrm{C}_{18}$ for the extraction of PAHs and phthalate esters in water samples [179] and lidocaine in rat plasma samples [180].

In addition, the $\mathrm{Fe}_{3} \mathrm{O}_{4} / \mathrm{SiO}_{2}$ core was functionalized with $\mathrm{C}_{18}$ for the extraction of PAHs [181] in water solutions, with polymerization (MAA-co-vinylbenzyl chloride-co-DVB) and poly (MAA-coEGDMA) for the extraction of amphetamines in urine samples and benzimidazole residues in animal tissue $[182,183]$. Some other polymers, such as polyaniline [184], polydopamine [185] and polypyrrole $[185,186]$, are used commonly. Also, surfactants, such as trimethylammonium bromide (CTAB) and sodium dodecyl sulfate (SDS) [187,188], are functionalized on the surface of the MNPs.

Recently, some novel materials grafted onto MNPs were reported. For example, an ion liquid, 1-hexadecyl-3-methylimidazolium bromide $\left(\mathrm{C}_{16} \mathrm{mimBr}\right)$-coated $\mathrm{Fe}_{3} \mathrm{O}_{4}$-MNPs as an adsorbent of mixed hemi micelles SPE, was investigated for the preconcentration of two chlorophenols (CPs) in environmental water samples prior to HPLCUV [189]. The LODs of the analytes were $0.12 \mu \mathrm{g} / \mathrm{L}$ and $0.13 \mu \mathrm{g} / \mathrm{L}$, respectively. Recoveries at three concentrations were $74-90 \%$.

A sorbent based on the aptamer for ochratoxin A was immobilized onto MNPs and used to develop a magnetic SPE of ochratoxin A in food samples in conjunction with HPLC separation and fluorescence detection [190]. The highly selective sorbents showed excellent extraction efficiency.

Long et al. [191] modified triphenylamine on the surface of MNPs as a new sorbent for the extraction of PAHs in water samples. This method enabled selective, sensitive analysis of PAHs in complex environmental water at low LODs of 0.04-3.75 ng/L, and high recoveries of $80.21-108.33 \%$.

For the selective extraction of PAHs from water and milk samples, biocompatible phosphatidylcholine bilayer and diphenyl were also coated on the MNPs and good results were obtained [192,193].

\subsubsection{Other metallic nanoparticles}

Among the metallic $\mathrm{Fe}_{3} \mathrm{O}_{4}, \mathrm{TiO}_{2}, \mathrm{Al}_{2} \mathrm{O}_{3}, \mathrm{ZrO}_{2}, \mathrm{MnO}$ and $\mathrm{CeO}_{2}$ nanomaterials modified with functional coatings as SPSs [40-47], $\mathrm{TiO}_{2}$ nanomaterials are also commonly used. As a new $\mathrm{TiO}_{2}$ nanomaterial, $\mathrm{TiO}_{2}$ nanotubes (NTs) have often been used as the photo catalyst for photo degradation. However, it should have much higher adsorption capacity and much greater potential for the trapping of compounds because it has a larger surface area [194]. For example, organophosphorus pesticides in water samples [194], benzoyl-urea insecticides [195] and polychlorinated biphenyls [196] in environmental water samples were extracted by SPE using $\mathrm{TiO}_{2}-$ NTs as SPSs. In $\mu \mathrm{SPE}, \mathrm{TiO}_{2}$-NTs were used to extract pyrethroid pesticides [46] and organochlorine pesticides [47] in water samples.

Some novel functionalized NTs were also reported. Zhou et al. [197] described a new method for rapid, sensitive determination of paraquat and diquat by SPE with an $\mathrm{N}$-doped $\mathrm{TiO}_{2}-\mathrm{NT}$ cartridge prior to CE. Under optimal conditions, the LODs were $1.95 \mathrm{mg} / \mathrm{L}$ and $2.59 \mathrm{mg} / \mathrm{L}$ for paraquat and diquat, respectively. The developed method was successfully applied to the analysis of paraquat and diquat in several environmental water samples.

Wang et al. [198] investigated $\mathrm{Zr}$-doped $\mathrm{TiO}_{2}$-NTs as SPSs for the enrichment of BPA in water samples. Under optimal conditions, an excellent linear range of $1-80 \mathrm{mg} / \mathrm{L}$ and an LOD of $0.016 \mathrm{mg} / \mathrm{L}$ were obtained. Four different real water samples were used for validation, and the spiked recoveries were satisfactory in the range 102.9-108.8\%.

Like $\mathrm{TiO}_{2}-\mathrm{NT}, \mathrm{TiO}_{2}$ wire was also introduced for SPSs. A novel SPME fiber was fabricated through the anodization of Ti-wire substrates in an electrolyte containing ethylene glycol and $\mathrm{NH}_{4} \mathrm{~F}$ [45]. The SPME fiber coupled with GC was then used to extract PAHs from real water samples, exhibiting high selectivity for PAHs.

Pan et al. [199] used the adsorbent of Ti wire, on which $\mathrm{TiO}_{2}$ NTs were first formed by anodization and then AuNPs and $n$-octadecanethiol were modified, for the extraction of PAHs in water samples.

\subsection{Metal-organic frameworks as solid-phase sorbents}

As mentioned above, MOFs are inorganic-organic solids that form porous crystalline structures and can be synthesized by using a wide range of metal ions and organic ligands [200]. Because of their unique properties, MOFs were increasingly used recently as SPSs.

Yan's group has widely explored the analytical applications of MOF materials, ranging from sample collection to chromatographic separation [201-205]. MOFs used as chromatographic solid phases were also investigated [206-208] \{e.g., a tubular MOF, MOF-CJ3, was chosen as stationary phase to prepare a capillary GC column via a verified dynamic coating procedure. The column offered good separations of linear and branched alkanes, as well as aromatic positional isomers [206]\}.

Some MOFs with modification are also used in chromatography separation. For example, a bipyridinium ligand with a charge separated skeleton was introduced into a MOF to yield a porous material with charge-polarized pore space, which exhibited selective adsorption for polar guest molecules and could be further used in GC for the separation of alcohol-water mixtures [207].

Yu et al. have reviewed some applications of MOFs as stationary phases in chromatography [209]. For sample preparation, Ouyang's group has reviewed MOFs as SPSs (e.g., for SPE and SPME) [210,211]. Yang et al. prepared and evaluated MOFs and used them as new SPE materials for the determination of PAHs in environmental waters, coupling with HPLC [212]. Under the optimized experimental conditions, good sensitivity levels were achieved with low LODs in the range $0.4-4.0 \mathrm{ng} / \mathrm{L}$ and a linearity $0.004-20 \mu \mathrm{g} / \mathrm{L}$ $\left(\mathrm{R}^{2}>0.996\right)$.

Since most of the biological and environmental samples contain water, water-stable MOFs are very popular in biological chemistry. For example, MOF MIL-101 was fabricated in a polyetheretherketone (PEEK) tube as micro-trapping device, and applied to sorptive extraction of naproxen and its metabolite in urine samples [213]. MIL-101 exhibited higher extraction capacity for naproxen than $C_{18}$ bonded silica and MWCNTs. The method proved to be highly sensitive with the linear range of $0.05-6.0 \mu \mathrm{g} / \mathrm{L}$ and LODs of $0.034 \mu \mathrm{g} / \mathrm{L}$ and $0.011 \mu \mathrm{g} / \mathrm{L}$ for naproxen and 6-O-desmethylnaproxen, respectively.

Novel PDMS/MOFs coated stir bars were prepared by sol-gel technique [214]. The PDMS/MOF coating for SBSE coupled with the HPLCUV method was developed for the determination of seven target estrogens in environmental waters. Under optimal experimental conditions, the LODs $(S / N=3)$ were found to be in the range 0.15 $0.35 \mu \mathrm{g} / \mathrm{L}$.

\section{Conclusions and perspectives}

This review of SPSs for sample preparation prior to chromatography includes an enormous variety of materials (e.g., MIPs, carbon nanomaterials, metallic NPs and MOFs). Undoubtedly, the use of SPSs in sample-preparation methods, such as SPE, SPME, MSPD and SBSE, has become a hot topic in analysis. In sample preparation, all SPSs 
Table 4

General advantages and disadvantages of various solid-phase sorbents (SPSs)

\begin{tabular}{|c|c|c|}
\hline SPSs & Advantages & Disadvantages \\
\hline MIPs & $\begin{array}{l}\text { Large specific surface area, low cost, easy synthesis, high stability } \\
\text { to harsh chemical, physical conditions, excellent reusability, } \\
\text { selective adsorbents for target analytes. }\end{array}$ & $\begin{array}{l}\text { Hard to imprinting water-soluble biological macromolecules and } \\
\text { hydrophilic compound, heterogeneous binding sites which have a } \\
\text { bad effect on binding, incompatibility with aqueous media, } \\
\text { leakage of template molecules. }\end{array}$ \\
\hline Carbon nanomaterials & $\begin{array}{l}\text { Large adsorption surface-to-volume ratios, high affinity, Easily } \\
\text { modified with functional groups and easily covalently or non- } \\
\text { covalently functionalized. }\end{array}$ & $\begin{array}{l}\text { Cause high pressure in the SPE column, easily escape from the SPE } \\
\text { column. }\end{array}$ \\
\hline Metallic nanoparticles & $\begin{array}{l}\text { Large specific surface area, high adsorption capacity, low } \\
\text { temperature modification, quickly isolated from matrix solutions } \\
\text { by using an external magnet, economical and highly efficient, } \\
\text { excellent reusability. }\end{array}$ & $\begin{array}{l}\text { Less selectivity, MNPs with functional groups on the surface tend } \\
\text { to aggregate in water solution, unsuitable for samples with } \\
\text { complicated matrices. }\end{array}$ \\
\hline MOFs & $\begin{array}{l}\text { Large surface areas, excellent adsorption capability for gaseous } \\
\text { molecules, easily embedded into organic polymers which was } \\
\text { good for SPME. }\end{array}$ & $\begin{array}{l}\text { Moisture sensitive (extraction efficiency decreases significantly } \\
\text { when applied to adsorption in aqueous matrix), microporous (the } \\
\text { small size of their cavities restricts the choice of incorporated } \\
\text { species and thus induces low diffusion rates). }\end{array}$ \\
\hline
\end{tabular}

have their own advantages and disadvantages, as outlined in Table 4. The common property of all the SPSs is their large specific surface area, which makes them very suitable as SPSs. However, every material has its own characteristics (e.g., carbon nanomaterials may cause high pressure in the SPE column, which is not favorable for the diffusion of target analytes). Also, because of the special properties of MOFs (e.g., excellent adsorption capability for gaseous molecules, and easily being embedded into organic polymers), they are very suitable as SPSs for SPME. The investigations reported not only included exploration of new SPSs that can overcome the disadvantages mentioned above, but also included exploration of new samplepreparation methods. Three major issues associated with their preparation and applications are yet to be resolved for continuous improvement of SPSs, as follows.

First, the primary requirements of SPSs are to possess high selectivity and enrichment capability (i.e., they can specifically adsorb targeted analytes while eliminating matrix interferences and thereby assist to attain high detectability). Each of the sorbents has their own advantages (e.g., MIPs have high selectivity, physical robustness, and thermal stability, low cost and easy preparation). New techniques and methods of synthesis are increasingly being developed for new SPSs with continually improved selectivity and other features. Significantly, vigorously developing combined SPSs by coupling various materials and their characteristics can rapidly advance SPSs, demonstrating improved selectivity and adsorption ability (e.g., MIPs coated on MNPs and G/GO).

Second, the major trends in the SPSs will be towards more MSPD and SBSE applications. Because of the traditional usage of SPE and easy operation of SPME, many research works have been reported on these two extraction techniques, including improving sorbents and instruments. However, although applications of MSPD and SBSE are still in their infancy, they could become tools, routinely used in sample preparation in the near future, especially for carbon NPs used in SBSE.

Third, the developments of on/in-line mode of extraction methods and monolithic columns will be accelerated to facilitate preparing more novel SPSs. In order to satisfy the general objectives of sample preparation, such as smaller sample amounts, reduction or elimination of organic solvents, integration of several preparation steps into one (e.g., applications of passive samplers for simultaneous sampling, extraction and enrichment of analytes from complicated matrices), and potential for automation, on/in-line mode of extraction methods and monolithic column are popular. We therefore strongly encourage new explorations of SPS-based monolithic column and extraction methods, and thereby push forward sample preparation.

\section{Acknowledgments}

Financial support is gratefully acknowledged from the National Natural Science Foundation of China (21275158, 21105117), Research and Training Foundation of Hainan Medical University (HY2013-04), the Strategic Priority Research Program of the Chinese Academy of Sciences (XDA11020405), and the 100 Talents Program of the Chinese Academy of Sciences.

\section{References}

[1] C.W. Huck, G.K. Bonn, Recent developments in polymer-based sorbents for solid-phase extraction, J. Chromatogr. A 885 (2000) 51-72.

[2] D.E. Raynie, Modern extraction techniques, Anal. Chem. 82 (2010) 4911-4916.

[3] D.E. Raynie, Modern extraction techniques, Anal. Chem. 78 (2006) 39974004.

[4] G. Alberti, V. Amendola, M. Pesavento, R. Biesuz, Beyond the synthesis of novel solid phases: review on modelling of sorption phenomena, Coord. Chem. Rev. 256 (2012) 28-45.

[5] L.X. Chen, S.F. Xu, J.H. Li, Recent advances in molecular imprinting technology: current status, challenges and highlighted applications, Chem. Soc. Rev. 40 (2011) 2922-2942.

[6] J.H. Lin, Z.H. Wu, W.L. Tseng, Extraction of environmental pollutants using magnetic nanomaterials, Anal. Methods 2 (2010) 1874-1879.

[7] R. Lucena, B.M. Simonet, S. Cárdenas, M. Valcárcel, Potential of nanoparticles in sample preparation, J. Chromatogr. A 1218 (2011) 620-637.

[8] E. Turiel, A. Martín-Esteban, Molecularly imprinted polymers for sample preparation: a review, Anal. Chim. Acta 668 (2010) 87-99.

[9] E. Turiel, A. Martín-Esteban, Molecularly imprinted polymers for solid-phase microextraction, J. Sep. Sci. 32 (2009) 3278-3284.

[10] F. Augusto, E. Carasek, R.G.C. Silva, S.R. Rivellino, A.D. Batista, E. Martendal, New sorbents for extraction and microextraction techniques, J. Chromatogr. A 1217 (2010) 2533-2542.

[11] M. Tankiewicz, J. Fenik, M. Biziuk, Solventless and solvent-minimized sample preparation techniques for determining currently used pesticides in water samples: a review, Talanta 86 (2011) 8-22.

[12] A. Mehdinia, M.O. Aziz-Zanjani, Advances for sensitive, rapid and selective extraction in different configurations of solid-phase microextraction, TrAC, Trends Anal. Chem. 51 (2013) 13-22.

[13] A. Spieteluna, Ł. Marcinkowskia, M. de la Guardiab, J. Namieśnik, Recent developments and future trends in solid phase microextraction techniques towards green analytical chemistry, J. Chromatogr. A 1321 (2013) 1-13.

[14] C. Yang, J. Wang, D.H. Li, Microextraction techniques for the determination of volatile and semivolatile organic compounds from plants: a review, Anal. Chim. Acta 799 (2013) 8-22.

[15] A. Namera, T. Saito, Recent advances in unique sample preparation techniques for bioanalysis, Bioanalysis 5 (2013) 915-932.

[16] J.H. Li, Z. Zhang, S.F. Xu, L.X. Chen, N. Zhou, H. Xiong, et al., Label-free colorimetric detection of trace cholesterol based on molecularly imprinted photonic hydrogels, J. Mater. Chem. 21 (2011) 19267-19274.

[17] Q.Z. Feng, L.X. Zhao, J.M. Lin, Molecularly imprinted polymer as micro-solid phase extraction combined with high performance liquid chromatography to determine phenolic compounds in environmental water samples, Anal. Chim. Acta 650 (2009) 70-76.

[18] J.H. Li, Y.Y. Wen, L.X. Chen, Advances of molecularly imprinted polymers for solid phase extraction, Chin. J. Chromatogr. 31 (2013) 181-184. 
[19] J.X. Liu, H. Chen, Z. Lin, J.M. Lin, Preparation of surface imprinting polymer capped Mn-doped $\mathrm{ZnS}$ quantum dots and their application for chemiluminescence detection of 4-nitrophenol in tap water, Anal. Chem. 82 (2010) 7380-7386.

[20] X.Q. Cai, J.H. Li, Z. Zhang, F.F. Yang, R.C. Dong, L.X. Chen, Novel $\mathrm{Pb}^{2+}$ ion imprinted polymers based on ionic interaction via synergy of dual functional monomers for selective solid-phase extraction of $\mathrm{Pb}^{2+}$ in water samples, ACS Appl. Mater. Interfaces 6 (2014) 305-313.

[21] H.W. Kroto, J.R. Heath, S.C.O. Brien, R.F. Curl, R.E. Smalley, C60: buckminsterfullerene, Nature 318 (1985) 162-163.

[22] L.M. Ravelo-Pérez, A.V. Herrera-Herrera, J. Hernández-Borges, M.Á. Rodríguez-Delgado, Carbon nanotubes: solid-phase extraction, J. Chromatogr. A 1217 (2010) 2618-2641.

[23] J.M. Jiménez-Soto, S. Cárdenas, M. Valcárcel, Evaluation of carbon nanocones/ disks as sorbent material for solid-phase extraction, J. Chromatogr. A 1216 (2009) 5626-5633.

[24] J.A. Nisha, M. Yudasaka, S. Bandow, F. Kokai, K. Takahashi, S. Iijima, Adsorption and catalytic properties of single-wall carbon nanohorns, Chem. Phys. Lett. 328 (2000) 381-386.

[25] S.L. Zhang, Z. Du, G.K. Li, Layer-by-layer fabrication of chemical-bonded graphene coating for solid-phase microextraction, Anal. Chem. 83 (2011) 7531-7541.

[26] W.H. Chen, S.C. Lee, S. Sabu, H.C. Fang, S.C. Chung, C.C. Han, et al., Solid phase extraction and elution on diamond (SPEED): a fast and general platform for proteome analysis with mass spectrometry, Anal. Chem. 78 (2006) 42284234.

[27] M. Gallego, Y.P. de Peña, M. Valcárcel, Fullerenes as sorbent materials for metal preconcentration, Anal. Chem. 66 (1994) 4074-4078.

[28] A. Serrano, M. Gallego, Fullerenes as sorbent materials for benzene, toluene, ethylbenzene, and xylene isomers preconcentration, J. Sep. Sci. 29 (2006) 33-40.

[29] B. Jurado-Sánchez, E. Ballesteros, M. Gallego, Fullerenes for aromatic and non-aromatic N-nitrosamines discrimination, J. Chromatogr. A 1216 (2009) 1200-1205.

[30] M. Valcárcel, S. Cárdenas, B.M. Simonet, Y. Moliner-Martínez, R. Lucena, Carbon nanostructures as sorbent materials in analytical processes, TrAC, Trends Anal. Chem. 27 (2008) 34-43.

[31] Y.Q. Cai, G.B. Jiang, J.F. Liu, Q.X. Zhou, Multiwalled carbon nanotubes as a solid-phase extraction adsorbent for the determination of bisphenol A, 4-n-nonylphenol, and 4-tert-octylphenol, Anal. Chem. 75 (2003) 2517-2521.

[32] B.T. Zhang, X.X. Zheng, H.F. Li, J.M. Lin, Application of carbon-based nanomaterials in sample preparation: a review, Anal. Chim. Acta 784 (2013) $1-17$.

[33] M.H. Ge, K. Sattler, Observation of fullerene cones, Chem. Phys. Lett. 220 (1994) 192-196.

[34] A. Krishnan, E. Dujardin, M.M.J. Treacy, J. Hugdahl, S. Lynum, T.W. Ebbesen, Graphitic cones and the nucleation of curved carbon surfaces, Nature 388 (1997) 451-454

[35] N.N. Bui, B.H. Kim, K.S. Yang, M.E. Dela Cruz, J.P. Ferraris, Activated carbon fibers from electrospinning of polyacrylonitrile/pitch blends, Carbon 47 (2009) 2538-2539.

[36] K.S. Novoselov, A.K. Geim, S.V. Morozov, D. Jiang, Y. Zhang, S.V. Dubonos, et al., Electric field effect in atomically thin carbon films, Science 306 (2004) 666-669.

[37] X.L. Fu, T.T. Lou, Z.P. Chen, M. Lin, W.W. Feng, L.X. Chen, “Turn-on” fluorescence detection of lead ions based on accelerated leaching of gold nanoparticles on the surface of grapheme, ACS Appl. Mater. Interfaces 4 (2012) 1080-1086.

[38] G. Chen, W. Weng, D. Wu, C. Wu, J. Lu, P. Wang, et al., Preparation and characterization of graphite nanosheets from ultrasonic powdering technique, Carbon 42 (2004) 753-759.

[39] D.R. Dreyer, S. Park, C.W. Bielawski, R.S. Ruoff, The chemistry of graphene oxide, Chem. Soc. Rev. 39 (2010) 228-240.

[40] C.Z. Jiang, Y. Sun, X. Yu, Y. Gao, L. Zhang, Y.P. Wang, et al., Liquid-solid extraction coupled with magnetic solid-phase extraction for determination of pyrethroid residues in vegetable samples by ultra-fast liquid chromatography, Talanta 114 (2013) 167-175.

[41] C.Y. Li, L.G. Chen, W. Li, Magnetic titanium oxide nanoparticles for hemimicelle extraction and HPLC determination of organophosphorus pesticides in environmental water, Microchim. Acta 180 (2013) 1109-1116.

[42] R. Behnam, M. Morshed, H. Tavanai, M. Ghiaci, Destructive adsorption of Diazinon pesticide by activated carbon nanofibers containing $\mathrm{Al}_{2} \mathrm{O}_{3}$ and $\mathrm{MgO}$ nanoparticles, Bull. Environ. Contam. Toxicol. 91 (2013) 475-480.

[43] H. Bagheri, R. Daliri, A. Roostaie, A novel magnetic poly (anilinenaphthylamine)-based nanocomposite for micro solid phase extraction of rhodamine B, Anal. Chim. Acta 794 (2013) 38-46.

[44] A. Ensafi, H. Karimi-Maleh, M. Ghiaci, M. Arshadi, Characterization of Mnnanoparticles decorated organo-functionalized $\mathrm{SiO}_{2}-\mathrm{Al}_{2} \mathrm{O}_{3}$ mixed-oxide as a novel electrochemical sensor: application for the voltammetric determination of captopril, J. Mater. Chem. 21 (2011) 15022-15030.

[45] H.M. Liu, D.A. Wang, L. Ji, J.B. Li, S.J. Liu, X. Liu, et al., A novel $\mathrm{TiO}_{2}$ nanotube array/Ti wire incorporated solid-phase microextraction fiber with high strength, efficiency and selectivity, J. Chromatogr. A 1217 (2010) 18981903.

[46] Y.R. Huang, Q.X. Zhou, J.P. Xiao, Establishment of trace determination method of pyrethroid pesticides with $\mathrm{TiO}_{2}$ nanotube array micro-solid phase equilibrium extraction combined with GC-ECD, Analyst 136 (2011) 2741-2746.
[47] Q.X. Zhou, Y.R. Huang, J.P. Xiao, G.H. Xie, Micro-solid phase equilibrium extraction with highly ordered $\mathrm{TiO}_{2}$ nanotube arrays: a new approach for the enrichment and measurement of organochlorine pesticides at trace level in environmental water samples, Anal. Bioanal. Chem. 400 (2011) 205-212.

[48] S.F. Xu, H.Z. Lu, X.W. Zheng, L.X. Chen, Stimuli-responsive molecularly imprinted polymers: versatile functional materials, J. Mater. Chem. C 1 (2013) 4406-4422.

[49] S.F. Xu, J.H. Li, X.L. Song, J.S. Liu, H.Z. Lu, L.X. Chen, Photonic and magnetic dual responsive molecularly imprinted polymers: preparation, recognition characteristics and properties as a novel sorbent for caffeine in complicated samples, Anal. Methods 5 (2013) 124-133.

[50] L. Fan, X.P. Yan, Evaluation of isostructural metal-organic frameworks coated capillary columns for the gas chromatographic separation of alkane isomers, Talanta 99 (2012) 944-950.

[51] O.M. Yaghi, M. O’Keeffe, N.W. Ockwig, H.K. Chae, M. Eddaoudi, J. Kim, Reticular synthesis and the design of new materials, Nature 423 (2003) 705-714.

[52] M. Eddaoudi, D.B. Moler, H. Li, B. Chen, T.M. Reineke, M. O’Keeffe, et al., Modular chemistry: secondary building units as a basis for the design of highly porous and robust metal-organic carboxylate frameworks, Acc. Chem. Res. 34 (2001) 319-330.

[53] J.L.C. Rowsell, O.M. Yaghi, Metal-organic frameworks: a new class of porous materials, Microporous Mesoporous Mater. 73 (2004) 3-14.

[54] J.R. Li, J. Sculley, H.C. Zhou, Metal-organic frameworks for separations, Chem. Rev. 112 (2012) 869-932.

[55] A. Corma, H. García, F.X. Llabrés i Xamena, Engineering metal organic frameworks for heterogeneous catalysis, Chem. Rev. 110 (2010) 4606-4655.

[56] S.M. Xie, Z.J. Zhang, Z.Y. Wang, L.M. Yuan, Chiral metal-organic frameworks for high-resolution gas chromatographic separations, J. Am. Chem. Soc. 133 (2011) 11892-11895.

[57] R.B. Getman, Y.S. Bae, C.E. Wilmer, R.Q. Snurr, Review and analysis of molecular simulations of methane, hydrogen, and acetylene storage in metal-organic frameworks, Chem. Rev. 112 (2011) 703-723.

[58] K.M.L. Taylor-Pashow, J.D. Rocca, Z. Xie, S. Tran, W. Lin, Post-synthetic modifications of iron-carboxylate nanoscale metal-organic frameworks for imaging and drug delivery, J. Am. Chem. Soc. 131 (2009) 14261-14263.

[59] Y.Y. Wen, J.H. Li, J.P. Ma, L.X. Chen, Recent advances in enrichment techniques to enhancing sensitivity in capillary electrophoresis, Electrophoresis 33 (2012) 2933-2952.

[60] F. Barahona, E. Turiel, A. Martín-Esteban, Molecularly imprinted polymer grafted to porous polyethylene frits: a new selective solid-phase extraction format, J. Chromatogr. A 1218 (2011) 7065-7070.

[61] V. Pakade, S. Lindahl, L. Chimuka, C. Turner, Molecularly imprinted polymers targeting quercetin in high-temperature aqueous solutions, J. Chromatogr. A 1230 (2012) 15-23.

[62] M. Javanbakht, M.H. Namjumanesh, B. Akbari-adergani, Molecularly imprinted solid-phase extraction for the selective determination of bromhexine in human serum and urine with high performance liquid chromatography, Talanta 80 (2009) 133-138.

[63] T. Jing, Y. Wang, Q. Dai, H. Xi, J.W. Niu, Q.L. Hao, et al., Preparation of mixedtemplates molecularly imprinted polymers and investigation of the recognition ability for tetracycline antibiotics, Biosens. Bioelectron. 25 (2010) 2218-2224

[64] H. Zeng, Y.Z. Wang, X.J. Liu, J.H. Kong, C. Nie, Preparation of molecular imprinted polymers using bi-functional monomer and bi-crosslinker for solid-phase extraction of rutin, Talanta 93 (2012) 172-181.

[65] M.D.C. López, M.C.C. Pérez, M.S.D. García, J.M.L. Vilariño, M.V.G. Rodríguez, L.F.B. Losada, Preparation, evaluation and characterization of quercetin-molecularly imprinted polymer for preconcentration and clean-up of catechins, Anal. Chim. Acta 721 (2012) 68-78.

[66] X.L. Song, J.H. Li, J.T. Wang, L.X. Chen, Quercetin molecularly imprinted polymers: preparation, recognition characteristics and properties as sorbent for solid-phase extraction, Talanta 80 (2009) 694-702.

[67] T. Muhammad, L. Cui, W. Jide, E.V. Piletska, A.R. Guerreiro, S.A. Piletsky, Rational design and synthesis of water-compatible molecularly imprinted polymers for selective solid phase extraction of amiodarone, Anal. Chim. Acta 709 (2012) 98-104.

[68] L. Zhang, F. Han, Y.Y. Hu, P. Zheng, X. Sheng, H. Sun, et al., Selective trace analysis of chloroacetamide herbicides in food samples using dummy molecularly imprinted solid phase extraction based on chemometrics and quantum chemistry, Anal. Chim. Acta 729 (2012) 36-44.

[69] D. De Smet, S. Monbaliu, P. Dubruel, C. Van Peteghem, E. Schacht, S. De Saeger, Synthesis and application of a T-2 toxin imprinted polymer, J. Chromatogr. A 1217 (2010) 2879-2886.

[70] Y.K. Lv, L.M. Wang, L. Yang, C.X. Zhao, H.W. Sun, Synthesis and application of molecularly imprinted poly(methacrylic acid)-silica hybrid composite material for selective solid-phase extraction and high-performance liquid chromatography determination of oxytetracycline residues in milk, J. Chromatogr. A 1227 (2012) 48-53.

[71] M. Abdouss, S. Azodi-Deilami, E. Asadi, Z. Shariatinia, Synthesis of molecularly imprinted polymer as a sorbent for solid phase extraction of citalopram from human serum and urine, J. Mater. Sci. Mater. Med. 23 (2012) 15431552.

[72] G.F. Zhu, J. Fan, Y.B. Gao, X. Gao, J.J. Wang, Synthesis of surface molecularly imprinted polymer and the selective solid phase extraction of imidazole from its structural analogs, Talanta 84 (2011) 1124-1132.

[73] R.N. Rao, P.K. Maurya, R. Kuntamukkala, W.D.V. Murali, V.N.K. Talluri, Molecularly imprinted polymer for selective extraction of 
3-methylflavone-8-carboxylic acid from human urine followed by its determination using zwitterionic hydrophilic interaction liquid chromatography, J. Sep. Sci. 34 (2011) 3265-3271.

[74] Y.M. Yin, Y.P. Chen, X.F. Wang, Y. Liu, H.L. Liu, M.X. Xie, Dummy molecularly imprinted polymers on silica particles for selective solid-phase extraction of tetrabromobisphenol A from water samples, J. Chromatogr. A 1220 (2012) 7-13.

[75] M.X. Huang, W.S. Pang, J. Zhang, S.D. Lin, J. Hu, A target analogue imprinted polymer for the recognition of antiplatelet active ingredients in Radix Salviae Miltiorrhizae by LC/MS/MS, J. Pharm. Biomed. Anal. 58 (2012) 12-18.

[76] Z. Zhang, S.F. Xu, J.H. Li, H. Xiong, H.L. Peng, L.X. Chen, Selective solid-phase extraction of Sudan I in chilli sauce by single-hole hollow molecularly imprinted polymers, J. Agric. Food Chem. 60 (2012) 180-187.

[77] S.F. Xu, J.H. Li, L.X. Chen, Molecularly imprinted core-shell nanoparticles for determination of trace atrazine by reversible addition-fragmentation chain transfer surface imprinting, J. Mater. Chem. 21 (2011) 4346-4351.

[78] S.F. Xu, L.X. Chen, J.H. Li, W. Qin, J.P. Ma, Preparation of hollow porous molecularly imprinted polymers and their applications to solid-phase extraction of triazines in soil samples, J. Mater. Chem. 21 (2011) 1204712053.

[79] X.Z. Shi, J.H. Liu, A.L. Sun, D.X. Li, J. Chen, Group-selective enrichment and determination of pyrethroid insecticides in aquaculture seawater via molecularly imprinted solid phase extraction coupled with gas chromatography-electron capture detection, J. Chromatogr. A 1227 (2012) 60-66.

[80] Z.L. Shen, D. Yuan, Q.D. Su, H. Zhang, J. Wang, J.H. Zhu, et al., Selective solid-phase extraction using molecular imprinted polymer for ananlysis of methamidophos in water and soil samples, Biosci. Biotechnol. Biochem. 75 (2011) 473-479.

[81] X.L. Song, J.H. Li, S.F. Xu, R.J. Ying, J.P. Ma, C.Y. Liao, et al., Determination of 16 polycyclic aromatic hydrocarbons in seawater using molecularly imprinted solid-phase extraction coupled with gas chromatography-mass spectrometry, Talanta 99 (2012) 75-82

[82] F. Canale, C. Cordero, C. Baggiani, P. Baravalle, C. Giovannoli, C. Bicchi, Development of a molecularly imprinted polymer for selective extraction of bisphenol A in water samples, J. Sep. Sci. 33 (2010) 1644-1651.

[83] H.Y. Yan, X.L. Cheng, G.L. Yang, Dummy molecularly imprinted solid-phase extraction for selective determination of five phthalate esters in plastic bottled functional beverages, J. Agric. Food Chem. 60 (2012) 5524-5531.

[84] R.J. Krupadam, B. Bhagat, M.S. Khan, Highly sensitive determination of polycyclic aromatic hydrocarbons in ambient air dust by gas chromatographymass spectrometry after molecularly imprinted polymer extraction, Anal. Bioanal. Chem. 397 (2010) 3097-3106.

[85] H.P. Zhu, L.G. Ma, G.Z. Fang, M.F. Pan, J.P. Lu, X.N. Wang, et al., Preparation of a molecularly imprinted polymer using TMB as a dummy template and its application as SPE sorbent for determination of six PBBs in water and fish samples, Anal, Methods 3 (2011) 393-399.

[86] S. Alsudir, Z. Iqbal, E.P.C. Lai, Competitive CE-UV binding tests for selective recognition of bisphenol A by molecularly imprinted polymer particles, Electrophoresis 33 (2012) 1255-1262.

[87] S.R. Mei, D. Wu, M. Jiang, B. Lu, J.M. Lim, Y.K. Zhou, et al., Determination of trace bisphenol A in complex samples using selective molecularly imprinted solid-phase extraction coupled with capillary electrophoresis, Microchem. J. 98 (2011) 150-155.

[88] Y. Peng, Y. Xie, J. Luo, L. Nie, Y. Chen, L.N. Chen, et al., Molecularly imprinted polymer layer-coated silica nanoparticles toward dispersive solid-phase extraction of trace sulfonylurea herbicides from soil and crop samples, Anal. Chim. Acta 674 (2010) 190-200.

[89] H. Ebrahimzadeh, H. Abedi, Y. Yamini, L. Adlnasab, Molecular-imprinted polymer extraction combined with dispersive liquid-liquid micro-extraction for ultra-preconcentration of mononitrotoluene, J. Sep. Sci. 33 (2010) 37593766.

[90] T.P. Lee, B. Saad, W.S. Khayoon, B. Salleh, Molecularly imprinted polymer as sorbent in micro-solid phase extraction of ochratoxin A in coffee, grape juice and urine, Talanta 88 (2012) 129-135.

[91] K. Demeestere, M. Petrović, M. Gros, J. Dewulf, H. Van Langenhove, D. Barceló, Trace analysis of antidepressants in environmental waters by molecularly imprinted polymer-based solid-phase extraction followed by ultraperformance liquid chromatography coupled to triple quadrupole mass spectrometry, Anal. Bioanal. Chem. 396 (2010) 825-837.

[92] M. Rejtharová, L. Rejthar, Determination of chloramphenicol in urine, feed water, milk and honey samples using molecular imprinted polymer clean-up, J. Chromatogr. A 1216 (2009) 8246-8253.

[93] M. Lombardo-Agüí, A.M. García-Campaña, L. Gámiz-Gracia, C.C. Blanco, Laser induced fluorescence coupled to capillary electrophoresis for the determination of fluoroquinolones in foods of animal origin using molecularly imprinted polymers, J. Chromatogr. A 1217 (2010) 2237-2242.

[94] Y. Hiratsuka, N. Funaya, H. Matsunaga, J. Haginaka, Preparation of magnetic molecularly imprinted polymers for bisphenol $\mathrm{A}$ and its analogues and their application to the assay of bisphenol A in river water, J. Pharm. Biomed. Anal. 75 (2013) 180-185.

[95] Z.K. Lin, Q.Y. He, L.T. Wang, X.D. Wang, Q.X. Dong, C.J. Huang, Preparation of magnetic multi-functional molecularly imprinted polymer beads for determining environmental estrogens in water samples, J. Hazard. Mater. 252-253 (2013) 57-63.

[96] Z.H. Zhang, X. Yang, H.B. Zhang, M.L. Zhang, L.J. Luo, Y.F. Hu, et al., Novel molecularly imprinted polymers based on multi-walled carbon nanotubes with binary functional monomer for the solid-phase extraction of erythromycin from chicken muscle, J. Chromatogr. B Anal. Technol. Biomed. Life Sci. 879 (2011) 1617-1624.

[97] R.X. Gao, X. Kong, F.H. Su, X.W. He, L.X. Chen, Y.K. Zhang, Synthesis and evaluation of molecularly imprinted core-shell carbon nanotubes for the determination of triclosan in environmental water samples, J. Chromatogr. A 1217 (2010) 8095-8102.

[98] C.D. Zhao, T. Zhao, X.Y. Liu, H.X. Zhang, A novel molecularly imprinted polymer for simultaneous extraction and determination of sudan dyes by on-line solid phase extraction and high performance liquid chromatography, J. Chromatogr. A 1217 (2010) 6995-7002.

[99] Z.X. Xu, J. Zhou, D.Y. Zhao, X.G. Qiao, J.M. Yang, Determination of trace para red residues in foods through on-line molecularly imprinted solid phase extraction coupled with high-performance liquid chromatography, J. Food Sci. 75 (2010) C49-C54

[100] H.M. Oliveira, M.A. Segundo, J.L.F.C. Lima, M. Miró, V. Cerdà, Exploiting automatic on-line renewable molecularly imprinted solid-phase extraction in lab-on-valve format as front end to liquid chromatography: application to the determination of riboflavin in foodstuffs, Anal. Bioanal. Chem. 397 (2010) 77-86.

[101] E. Rodríguez, F. Navarro-Villoslada, E. Benito-Peña, M.D. Marazuela, M.C. Moreno-Bondi, Multiresidue determination of ultratrace levels of fluoroquinolone antimicrobials in drinking and aquaculture water samples by automated online molecularly imprinted solid phase extraction and liquid chromatography, Anal. Chem. 83 (2011) 2046-2055.

[102] T. Jing, J.W. Niu, H. Xia, Q. Dai, H.Y. Zheng, Q.L. Hao, et al., Online coupling of molecularly imprinted solid-phase extraction to HPLC for determination of trace tetracycline antibiotic residues in egg samples, J. Sep. Sci. 34 (2011) 1469-1476.

[103] W. Boonjob, Y.L. Yu, M. Miró, M.A. Segundo, J.H. Wang, V. Cerdà, Online hyphenation of multimodal micro-solid phase extraction involving renewable molecularly imprinted and reversed-phase sorbents to liquid chromatography for automatic multiresidue assays, Anal. Chem. 82 (2010) 3052-3060.

[104] C.D. Zhao, X.M. Guan, X.Y. Liu, H.X. Zhang, Synthesis of molecularly imprinted polymer using attapulgite as matrix by ultrasonic irradiation for simultaneous on-line solid phase extraction and high performance liquid chromatography determination of four estrogens, J. Chromatogr. A 1229 (2012) 72-78.

[105] L. Guo, Q.L. Deng, G.Z. Fang, W. Gao, W. Shuo, Preparation and evaluation of molecularly imprinted ionic liquids polymer as sorbent for on-line solid-phase extraction of chlorsulfuron in environmental water samples, J. Chromatogr. A 1218 (2011) 6271-6277.

[106] Z.H. Zhang, H.B. Zhang, Y.F. Hu, S.Z. Yao, Synthesis and application of multiwalled carbon nanotubes-molecularly imprinted sol-gel composite material for on-line solid-phase extraction and high-performance liquid chromatography determination of trace Sudan IV, Anal. Chim. Acta 661 (2010) $173-180$.

[107] B. Sellergren, Direct drug determination by selective sample enrichment on an imprinted polymer, Anal. Chem. 66 (1994) 1578-1582.

[108] F.J. Lara, F. Lynen, P. Sandra, A.M. García-Campaña, F. Alés-Barrero, Evaluation of a molecularly imprinted polymer as in-line concentrator in capillary electrophoresis, Electrophoresis 29 (2008) 3834-3841.

[109] X.F. Zhang, S.X. Xu, Y.I. Lee, S.A. Soper, LED-induced in-column molecular imprinting for solid phase extraction/capillary electrophoresis, Analyst 138 (2013) 2821-2824.

[110] C. Zheng, Y.P. Huang, Z.S. Liu, Recent developments and applications of molecularly imprinted monolithic column for HPLC and CEC, J. Sep. Sci. 34 (2011) 1988-2002.

[111] Y.L. Hu, Y.Y. Wang, X.G. Chen, Y.F. Hu, G.K. Li, A novel molecularly imprinted solid-phase microextraction fiber coupled with high performance liquid chromatography for analysis of trace estrogens in fishery samples, Talanta 80 (2010) 2099-2105.

[112] M.A. Golsefidi, Z. Es'haghi, A. Sarafraz-Yazdi, Design, synthesis and evaluation of a molecularly imprinted polymer for hollow fiber-solid phase microextraction of chlorogenic acid in medicinal plants, J. Chromatogr. A 1229 (2012) 24-29.

[113] A.R. Khorrami, A. Rashidpur, Development of a fiber coating based on molecular sol-gel imprinting technology for selective solid-phase micro extraction of caffeine from human serum and determination by gas chromatography/mass spectrometry, Anal. Chim. Acta 727 (2012) 2025.

[114] D. Djozan, B. Ebrahimi, M. Mahkam, M.A. Farajzadeh, Evaluation of a new method for chemical coating of aluminum wire with molecularly imprinted polymer layer. Application for the fabrication of triazines selective solid-phase microextraction fiber, Anal. Chim. Acta 674 (2010) 40-48.

[115] X.G. Hu, Q.L. Cai, Y.N. Fan, T.T. Ye, Y.J. Cao, C.J. Guo, Molecularly imprinted polymer coated solid-phase microextraction fibers for determination of Sudan I-IV dyes in hot chili powder and poultry feed samples, J. Chromatogr. A 1219 (2012) 39-46.

[116] D.L. Deng, J.Y. Zhang, C. Chen, X.L. Hou, Y.Y. Su, L. Wu, Monolithic molecular imprinted polymer fiber for recognition and solid phase microextraction of ephedrine and pseudoephedrine in biological samples prior to capillary electrophoresis analysis, J. Chromatogr. A 1219 (2012) 195-200.

[117] F. Tan, M.J. Deng, X. Liu, H.X. Zhao, X.N. Li, X. Quan, et al., Evaluation of a novel microextraction technique for aqueous samples: porous membrane envelope filled with multiwalled carbon nanotubes coated with molecularly imprinted polymer, J. Sep. Sci. 34 (2011) 707-715. 
[118] L.J. Qiu, W. Liu, M. Huang, L. Zhang, Preparation and application of solid-phase microextraction fiber based on molecularly imprinted polymer for determination of anabolic steroids in complicated samples, J. Chromatogr. A 1217 (2010) 7461-7470.

[119] A. Prieto, A. Vallejo, O. Zuloaga, A. Paschke, B. Sellergen, E. Schillinger, et al., Selective determination of estrogenic compounds in water by microextraction by packed sorbents and a molecularly imprinted polymer coupled with large volume injection-in-port-derivatization gas chromatography-mass spectrometry, Anal. Chim. Acta 703 (2011) 41-51.

[120] J. Li, H.X. Chen, H. Chen, Y. Ye, Selective determination of trace thiamphenicol in milk and honey by molecularly imprinted polymer monolith microextraction and high-performance liquid chromatography, J. Sep. Sci. 35 (2012) 137-144.

[121] F. Barahona, E. Turiel, A. Martín-Esteban, Supported liquid membrane-protected molecularly imprinted fibre for solid-phase microextraction of thiabendazole, Anal. Chim. Acta 694 (2011) 83-89.

[122] A. Prieto, S. Schrader, C. Bauer, M. Möder, Synthesis of a molecularly imprinted polymer and its application for microextraction by packed sorbent for the determination of fluoroquinolone related compounds in water, Anal. Chim. Acta 685 (2011) 146-152.

[123] F.X. Qiao, H.Y. Yan, Simultaneous analysis of fluoroquinolones and xanthine derivatives in serum by molecularly imprinted matrix solid-phase dispersion coupled with liquid chromatography, J. Chromatogr. B Anal. Technol. Biomed. Life Sci. 879 (2011) 3551-3555.

[124] Y.Y. Wen, L.X. Chen, J.H. Li, Y.L. Ma, S.F. Xu, Z. Zhang, et al., Molecularly imprinted matrix solid-phase dispersion coupled to micellar electrokinetic chromatography for simultaneous determination of triazines in soil, fruit, and vegetable samples, Electrophoresis 33 (2012) 2454-2463.

[125] Y.L. Hu, J.W. Li, Y.F. Hu, G.K. Li, Development of selective and chemically stable coating for stir bar sorptive extraction by molecularly imprinted technique, Talanta 82 (2010) 464-470.

[126] Y.L. Hu, J.W. Li, G.K. Li, Synthesis and application of a novel molecularly imprinted polymer-coated stir bar for microextraction of triazole fungicides in soil, J. Sep. Sci. 34 (2011) 1190-1197.

[127] V.H. Springer, A.G. Lista, A simple and fast method for chlorsulfuron and metsulfuron methyl determination in water samples using multiwalled carbon nanotubes (MWCNTs) and capillary electrophoresis, Talanta 83 (2010) 126129.

[128] J. Sánchez-González, N. García-Otero, A. Moreda-Piñeiro, P. Bermejo-Barrera, Multi-walled carbon nanotubes-solid phase extraction for isolating marine dissolved organic matter before characterization by size exclusion chromatography, Microchem. J. 102 (2012) 75-82.

[129] J.P. Ma, R.H. Xiao, J.H. Li, J.B. Yu, Y.Q. Zhang, L.X. Chen, Determination of 16 polycyclic aromatic hydrocarbons in environmental water samples by solidphase extraction using multi-walled carbon nanotubes as adsorbent coupled with gas chromatography-mass spectrometry, J. Chromatogr. A 1217 (2010) 5462-5469.

[130] R. Su, X. Xu, X.H. Wang, D. Li, X.Y. Li, H.Q. Zhang, et al., Determination of organophosphorus pesticides in peanut oil by dispersive solid phase extraction gas chromatography-mass spectrometry, J. Chromatogr. B Anal. Technol. Biomed. Life Sci. 879 (2011) 3423-3428.

[131] P.Y. Zhao, L. Wang, J.H. Luo, J.G. Li, C.P. Pan, Determination of pesticide residues in complex matrices using multi-walled carbon nanotubes as reverseddispersive solid phase extraction sorbent, J. Sep. Sci. 35 (2012) 153-158.

[132] A.V. Herrera-Herrera, L.M. Ravelo-Pérez, J. Hernández-Borges, M.M. Afonso, J.A. Palenzuela, M.Á. Rodríguez-Delgado, Oxidized multi-walled carbon nanotubes for the dispersive solid-phase extraction of quinolone antibiotics from water samples using capillary electrophoresis and large volume sample stacking with polarity switching, J. Chromatogr. A 1218 (2011) 5352-5361.

[133] L. Guo, H.K. Lee, Development of multiwalled carbon nanotubes based micro-solid-phase extraction for the determination of trace levels of sixteen polycyclic aromatic hydrocarbons in environmental water samples, J. Chromatogr. A 1218 (2011) 9321-9327.

[134] H. Wu, X.C. Wang, B. Liu, J. Lu, B.X. Du, L.X. Zhang, et al., Flow injection solid-phase extraction using multi-walled carbon nanotubes packed microcolumn for the determination of polycyclic aromatic hydrocarbons in water by gas chromatography-mass spectrometry, J. Chromatogr. A 1217 (2010) 2911-2917.

[135] Y.N. Jiao, L. Ding, S.L. Fu, S.H. Zhu, H. Li, L.B. Wang, Determination of bisphenol $\mathrm{A}$, bisphenol $\mathrm{F}$ and their diglycidyl ethers in environmental water by solid phase extraction using magnetic multiwalled carbon nanotubes followed by GC-MS/MS, Anal. Methods 4 (2012) 291-298

[136] Y.B. Luo, Q.W. Yu, B.F. Yuan, Y.Q. Feng, Fast microextraction of phthalate acid esters from beverage, environmental water and perfume samples by magnetic multi-walled carbon nanotubes, Talanta 90 (2012) 123-131.

[137] Y. Guan, C. Jiang, C.F. Hu, L. Jia, Preparation of multi-walled carbon nanotubes functionalized magnetic particles by sol-gel technology and its application in extraction of estrogens, Talanta 83 (2010) 337-343.

[138] H.F. Zhang, Y.P. Shi, Preparation of $\mathrm{Fe}_{3} \mathrm{O}_{4}$ nanoparticle enclosure hydroxylated multi-walled carbon nanotubes for the determination of aconitines in human serum samples, Anal. Chim. Acta 724 (2012) 54-60.

[139] P.K. Kanaujia, D. Pardasani, A.K. Purohit, V. Tak, D.K. Dubey, Polyelectrolyte functionalized multi-walled carbon nanotubes as strong anion-exchange material for the extraction of acidic degradation products of nerve agents, J. Chromatogr. A 1218 (2011) 9307-9313.

[140] A. Sarafraz-Yazdi, A. Amiri, G. Rounaghi, H.E. Hosseini, A novel solid-phase microextraction using coated fiber based sol-gel technique using poly(ethylene glycol) grafted multi-walled carbon nanotubes for determination of benzene, toluene, ethylbenzene and o-xylene in water samples with gas chromatography-flam ionization detector, J. Chromatogr. A 1218 (2011) 5757-5764.

[141] A. Sarafraz-Yazd, F. Ghaemi, A. Amiri, Comparative study of the sol-gel based solid phase microextraction fibers in extraction of naphthalene, fluorene, anthracene and phenanthrene from saffron samples extractants, Microchim. Acta 176 (2012) 317-325.

[142] A. Sarafraz-Yazdi, M. Abbasian, A. Amiri, Determination of furan in food samples using two solid phase microextraction fibers based on sol-gel technique with gas chromatography-flame ionization detector, Food Chem. 131 (2012) 698-704.

[143] A. Sarafraz-Yazdi, A. Amiri, G. Rounaghi, H. Eshtiagh-Hosseini, Determination of non-steroidal anti-inflammatory drugs in water samples by solid-phase microextraction based sol-gel technique using poly(ethylene glycol) grafted multi-walled carbon nanotubes coated fiber, Anal. Chim. Acta 720 (2012) 134-141.

[144] Z. Es'haghi, Z. Rezaeifar, G.H. Rounaghi, Z.A. Nezhadi, M.A. Golsefidi, Synthesis and application of a novel solid-phase microextraction adsorbent: hollow fiber supported carbon nanotube reinforced sol-gel for determination of phenobarbital, Anal. Chim. Acta 689 (2011) 122-128.

[145] H. Bagheri, Z. Ayazi, H. Sistani, Chemically bonded carbon nanotubes on modified gold substrate as novel unbreakable solid phase microextraction fiber Microchim. Acta 174 (2011) 295-301.

[146] J.J. Feng, M. Sun, L.L. Xu, J.B. Li, X. Liu, S.X. Jiang, Preparation of metal wire supported solid phase microextraction fiber coated with multi-walled carbon nanotubes, J. Sep. Sci. 34 (2011) 2482-2488.

[147] X.X. Ma, Q.L. Li, D.X. Yuan, Determination of endocrine-disrupting compounds in water by carbon nanotubes solid-phase microextraction fiber coupled online with high performance liquid chromatography, Talanta 85 (2011) 2212 2217.

[148] R. Su, X.H. Wang, X. Xu, Z.M. Wang, D. Li, X. Zhao, et al., Application of multiwall carbon nanotubes-based matrix solid phase dispersion extraction for determination of hormones in butter by gas chromatography mass spectrometry, J. Chromatogr. A 1218 (2011) 5047-5054.

[149] S.X. Guan, Z.G. Yu, H.N. Yu, C.H. Song, Z.Q. Song, Z. Qin, Multi-walled carbon nanotubes as matrix solid-phase dispersion extraction adsorbent for simultaneous analysis of residues of nine organophosphorus pesticides in fruit and vegetables by rapid resolution LC-MS-MS, Chromatographia 73 (2011) 33-41.

[150] R. Sitko, B. Zawisza, E. Malicka, Graphene as a new sorbent in analytical chemistry, TrAC, Trends Anal. Chem. 51 (2013) 33-43.

[151] Q. Liu, J.B. Shi, L.X. Zeng, T. Wang, Y.Q. Cai, G.B. Jiang, Evaluation of graphene as an advantageous adsorbent for solid-phase extraction with chlorophenols as model analytes, J. Chromatogr. A 1218 (2011) 197-204.

[152] K.J. Huang, S. Yu, J. Li, Z.W. Wu, C.Y. Wei, Extraction of neurotransmitters from rat brain using graphene as a solid-phase sorbent, and their fluorescent detection by HPLC, Microchim. Acta 176 (2012) 327-335.

[153] G.Y. Zhao, S.J. Song, C. Wang, Q.H. Wu, Z. Wang, Determination of triazine herbicides in environmental water samples by high-performance liquid chromatography using graphene-coated magnetic nanoparticles as adsorbent, Anal. Chim. Acta 708 (2011) 155-159.

[154] W.N. Wang, Y.P. Li, Q.H. Wu, C. Wang, X.H. Zang, Z. Wang, Extraction of neonicotinoid insecticides from environmental water samples with magnetic graphene nanoparticles as adsorbent followed by determination with HPLC, Anal. Methods 4 (2012) 766-772.

[155] Q.H. Wu, M. Liu, X.X. Ma, W.N. Wang, C. Wang, X.H. Zang, et al., Extraction of phthalate esters from water and beverages using a graphene-based magnetic nanocomposite prior to their determination by HPLC, Microchim. Acta 177 (2012) 23-30.

[156] Q.H. Wu, G.Y. Zhao, C. Feng, C. Wang, Z. Wang, Preparation of a graphene-based magnetic nanocomposite for the extraction of carbamate pesticides from environmental water samples, J. Chromatogr. A 1218 (2011) 7936-7942.

[157] L. Xu, H.K. Lee, Novel approach to microwave-assisted extraction and microsolid-phase extraction from soil using graphite fibers as sorbent, J. Chromatogr. A 1192 (2008) 203-207.

[158] H. Zhang, W.P. Low, H.K. Lee, Evaluation of sulfonated graphene sheets as sorbent for micro-solid-phase extraction combined with gas chromatographymass spectrometry, J. Chromatogr. A 1233 (2012) 16-21.

[159] G.Y. Zhao, S.J. Song, C. Wang, Q.H. Wu, Z. Wang, Solid-phase microextraction with a novel graphene-coated fiber coupled with high-performance liquid chromatography for the determination of some carbamates in water samples, Anal. Methods 3 (2011) 2929-2935.

[160] H. Zhang, H.K. Lee, Plunger-in-needle solid-phase microextraction with graphene-based sol-gel coating as sorbent for determination of polybrominated diphenyl ethers, J. Chromatogr. A 1218 (2011) 4509-4516.

[161] Q.H. Wu, C. Feng, G.Y. Zhao, C. Wang, Z. Wang, Graphene-coated fiber for solid-phase microextraction of triazine herbicides in water samples, J. Sep. Sci. 35 (2012) 193-199.

[162] V.K. Ponnusamy, J.F. Jen, A novel graphene nanosheets coated stainless steel fiber for microwave assisted headspace solid phase microextraction of organochlorine pesticides in aqueous samples followed by gas chromatography with electron capture detection, J. Chromatogr. A 1218 (2011) 6861-6868.

[163] J.M. Chen, J. Zou, J.B. Zeng, X.H. Song, J.J. Ji, Y.R. Wang, et al., Preparation and evaluation of graphene-coated solid-phase microextraction fiber, Anal. Chim. Acta 678 (2010) 44-49. 
[164] J. Zou, X.H. Song, J.J. Ji, W.C. Xu, J.M. Chen, Y.Q. Jiang, et al., Polypyrrole/graphene composite-coated fiber for the solid-phase microextraction of phenols, J. Sep. Sci. 34 (2011) 2765-2772.

[165] L.L. Xu, J.J. Feng, J.B. Li, X. Liu, S.X. Jiang, Graphene oxide bonded fused-silica fiber for solid-phase microextraction-gas chromatography of polycyclic aromatic hydrocarbons in water, J. Sep. Sci. 35 (2012) 93-100.

[166] Y.B. Luo, J.S. Cheng, Q. Ma, Y.Q. Feng, J.H. Li, Graphene-polymer composite: extraction of polycyclic aromatic hydrocarbons from water samples by stir rod sorptive extraction, Anal. Methods 3 (2011) 92-98.

[167] Q. Liu, J.B. Shi, J.T. Sun, T. Wang, L.X. Zeng, N.L. Zhu, et al., Graphene-assisted matrix solid-phase dispersion for extraction of polybrominated diphenyl ethers and their methoxylated and hydroxylated analogs from environmental samples, Anal. Chim. Acta 708 (2011) 61-68.

[168] J.M. Jiménez-Soto, S. Cárdenas, M. Valcárcel, Evaluation of single-walled carbon nanohorns as sorbent in dispersive micro solid-phase extraction, Anal. Chim. Acta 714 (2012) 76-81.

[169] J.M. Jiménez-Soto, S. Cárdenas, M. Valcárcel, Dispersive micro solid-phase extraction of triazines from waters using oxidized single-walled carbon nanohorns as sorbent, J. Chromatogr. A 1245 (2012) 17-23.

[170] J.M. Jiménez-Soto, S. Cárdenas, M. Valcárcel, Carbon nanocones/disks as new coating for solid-phase microextraction, J. Chromatogr. A 1217 (2010) 3341 3347.

[171] W. Boonjob, M. Miró, M.A. Segundo, V. Cerdà, Flow-through dispersed carbon nanofiber-based microsolid-phase extraction coupled to liquid chromatography for automatic determination of trace levels of priority environmental pollutants, Anal. Chem. 83 (2011) 5237-5244.

[172] S. Vadukumpully, C. Basheer, C.S. Jeng, S. Valiyaveettil, Carbon nanofibers extracted from soot as a sorbent for the determination of aromatic amines from wastewater effluent samples, J. Chromatogr. A 1218 (2011) 3581-3587.

[173] J.W. Zewe, J.K. Steach, S.V. Olesik, Electrospun fibers for solid-phase microextraction, Anal. Chem. 82 (2010) 5341-5348.

[174] L.G. Chen, T. Wang, J. Tong, Application of derivatized magnetic materials to the separation and the preconcentration of pollutants in water samples, TrAC, Trends Anal. Chem. 30 (2011) 1095-1108.

[175] S.W. Su, Y.C. Liao, C.W. Zhang, Analysis of alendronate in human urine and plasma by magnetic solid-phase extraction and capillary electrophoresis with fluorescence detection, J. Sep. Sci. 35 (2012) 681-687.

[176] C.C. Hsu, C.W. Whang, Microscale solid phase extraction of glyphosate and aminomethylphosphonic acid in water and guava fruit extract using aluminacoated iron oxide nanoparticles followed by capillary electrophoresis and electrochemiluminescence detection, J. Chromatogr. A 1216 (2009) 8575-8580.

[177] Y.Y. Geng, M.Y. Ding, H. Chen, H.F. Li, J.M. Lin, Preparation of hydrophilic carbon-functionalized magnetic microspheres coated with chitosan and application in solid-phase extraction of bisphenol $\mathrm{A}$ in aqueous samples, Talanta 89 (2012) 189-194.

[178] S.X. Zhang, H.Y. Niu, Z.J. Hu, Y.Q. Cai, Y.L. Shi, Preparation of carbon coated Fe304 nanoparticles and their application for solid-phase extraction of polycyclic aromatic hydrocarbons from environmental water samples, J. Chromatogr. A 1217 (2010) 4757-4764.

[179] S.X. Zhang, H.Y. Niu, Y.Q. Cai, Y.L. Shi, Barium alginate caged $\mathrm{Fe}_{3} \mathrm{O}_{4} @ \mathrm{C}_{18}$ magnetic nanoparticles for the pre-concentration of polycyclic aromatic hydrocarbons and phthalate esters from environmental water samples, Anal. Chim. Acta 665 (2010) 167-175.

[180] B. Chu, D.J. Lou, P.F. Yu, S.N. Hu, S. Shen, Development of an on-column enrichment technique based on $\mathrm{C}_{18}$-functionalized magnetic silica nanoparticles for the determination of lidocaine in rat plasma by high performance liquid chromatography, J. Chromatogr. A 1218 (2011) 7248-7253.

[181] X.L. Zhang, H.Y. Niu, W.H. Li, Y.L. Shi, Y.Q. Cai, A core-shell magnetic mesoporous silica sorbent for organic targets with high extraction performance and anti-interference ability, Chem. Commun. 47 (2011) 4454-4456.

[182] Q. Gao, C.Y. Lin, D. Luo, L.L. Suo, J.L. Chen, Y.Q. Feng, Magnetic solid-phase extraction using magnetic hyper cross linked polymer for rapid determination of illegal drugs in urine, J. Sep. Sci. 34 (2011) 3083-3091.

[183] X.Z. Hu, M.L. Chen, Q. Gao, Q.W. Yu, Y.Q. Feng, Determination of benzimidazole residues in animal tissue samples by combination of magnetic solid-phase extraction with capillary zone electrophoresis, Talanta 89 (2012) 335-341.

[184] A. Mehdinia, F. Roohi, A. Jabbari, Rapid magnetic solid phase extraction with in situ derivatization of methylmercury in seawater by $\mathrm{Fe}_{3} \mathrm{O}_{4} /$ polyaniline nanoparticle, J. Chromatogr. A 1218 (2011) 4269-4274.

[185] Z. Iqbal, S. Alsudir, M. Miah, E.P.C. Lai, Rapid CE-UV binding tests of environmentally hazardous compounds with polymer-modified magnetic nanoparticles, Electrophoresis 32 (2011) 2181-2187.

[186] J.R. Meng, J. Bu, C.H. Deng, X.M. Zhang, Preparation of polypyrrole-coated magnetic particles for micro solid-phase extraction of phthalates in water by gas chromatography-mass spectrometry analysis, J. Chromatogr. A 1218 (2011) 1585-1591.

[187] J. Ding, Q. Zhao, L. Sun, L. Ding, N.Q. Ren, Magnetic mixed hemimicelles solid phase extraction of xanthohumol in beer coupled with high-performance liquid chromatography determination, J. Sep. Sci. 34 (2011) 1463-1468.

[188] H. Bagheri, O. Zandi, A. Aghakhani, Reprint of: extraction of fluoxetine from aquatic and urine samples using sodium dodecyl sulfate-coated iron oxide magnetic nanoparticles followed by spectrofluorimetric determination, Anal. Chim. Acta 716 (2012) 61-65.

[189] Q. Cheng, F. Qu, N.B. Li, H.Q. Luo, Mixed hemimicelles solid-phase extraction of chlorophenols in environmental water samples with 1-hexadecyl-3methylimidazolium bromide-coated $\mathrm{Fe}_{3} \mathrm{O}_{4}$ magnetic nanoparticles with high-performance liquid chromatographic analysis, Anal. Chim. Acta 715 (2012) 113-119.

[190] X.M. Wu, J. Hu, B.H. Zhu, L. Lu, X.D. Huang, D.W. Pang, Aptamer-targeted magnetic nanospheres as a solid-phase extraction sorbent for determination of ochratoxin A in food samples, J. Chromatogr. A 1218 (2011) 7341-7346.

[191] Y.M. Long, Y.Z. Chen, F. Yang, C.Y. Chen, D. Pan, Q.Y. Cai, et al., Triphenylaminefunctionalized magnetic microparticles as a new adsorbent coupled with high performance liquid chromatography for the analysis of trace polycyclic aromatic hydrocarbons in aqueous samples, Analyst 137 (2012) 2716-2722.

[192] S.X. Zhang, H.Y. Niu, Y.Y. Zhang, J.S. Liu, Y.L. Shi, X.L. Zhang, et al., Biocompatible phosphatidylcholine bilayer coated on magnetic nanoparticles and their application in the extraction of several polycyclic aromatic hydrocarbons from environmental water and milk samples, J. Chromatogr. A 1238 (2012) 3845.

[193] F. Bianchi, V. Chiesi, F. Casoli, P. Luches, L. Nasi, M. Careri, et al., Magnetic solid-phase extraction based on diphenyl functionalization of $\mathrm{Fe}_{3} \mathrm{O}_{4}$ magnetic nanoparticles for the determination of polycyclic aromatic hydrocarbons in urine samples, J. Chromatogr. A 1231 (2012) 8-15.

[194] Y.R. Huang, Q.X. Zhou, J.P. Xiao, G.H. Xie, Determination of trace organophosphorus pesticides in water samples with $\mathrm{TiO} 2$ nanotubes cartridge prior to GC-flame photometric detection, J. Sep. Sci. 33 (2010) 2184-2190.

[195] Y.R. Huang, Q.X. Zhou, G.H. Xie, H.J. Liu, H.Y. Lin, Titanium dioxide nanotubes for solid phase extraction of benzoylurea insecticides in environmental water samples, and determination by high performance liquid chromatography with UV detection, Microchim. Acta 172 (2011) 109-115.

[196] Q.X. Zhou, Y.R. Huang, G.H. Xie, Investigation of the applicability of highly ordered $\mathrm{TiO}_{2}$ nanotube array for enrichment and determination of polychlorinated biphenyls at trace level in environmental water samples, J. Chromatogr. A 1237 (2012) 24-29.

[197] Q.X. Zhou, J.L. Mao, J.P. Xiao, G.H. Xie, Determination of paraquat and diquat preconcentrated with $\mathrm{N}$ doped $\mathrm{TiO}_{2}$ nanotubes solid phase extraction cartridge prior to capillary electrophoresis, Anal. Methods 2 (2010) 1063-1068.

[198] X.F. Wang, Q.X. Zhou, M.X. Zhai, Using $\mathrm{Zr}$ doped $\mathrm{TiO}_{2}$ nanotubes for the pre-concentration and sensitive determination of bisphenol A prior to fluorescence spectrometry in water samples, Anal. Methods 4 (2012) 394-398.

[199] D. Pan, C.Y. Chen, F. Yang, Y.M. Long, Q.Y. Cai, S.Z. Yao, Titanium wire-based SPE coupled with HPLC for the analysis of PAHs in water samples, Analyst 136 (2011) 4774-4779.

[200] L.J. Murray, M. Dinca, J.R. Long, Hydrogen storage in metal-organic frameworks, Chem. Soc. Rev. 38 (2009) 1294-1314

[201] L.M. Li, F. Yang, H.F. Wang, X.P. Yan, Metal-organic framework polymethyl methacrylate composites for open-tubular capillary electrochromatography, J. Chromatogr. A 1316 (2013) 97-103.

[202] X.Q. Yang, C.X. Yang, X.P. Yan, Zeolite imidazolate framework-8 as sorbent for on-line solid-phase extraction coupled with high-performance liquid chromatography for the determination of tetracyclines in water and milk samples, J. Chromatogr. A 1304 (2013) 28-33.

[203] N. Chang, X.P. Yan, Exploring reverse shape selectivity and molecular sieving effect of metal-organic framework UIO-66 coated capillary column for gas chromatographic separation, J. Chromatogr. A 1257 (2012) 116-124.

[204] Y.Y. Fu, C.X. Yang, X.P. Yan, Metal-organic framework MIL-100 (Fe) as the stationary phase for both normal-phase and reverse-phase high performance liquid chromatography, J. Chromatogr. A 1274 (2013) 137-144.

[205] Y.Y. Fu, C.X. Yang, X.P. Yan, Fabrication of ZIF-8@SiO 2 core-shell microspheres as the stationary phase for high-performance liquid chromatography, Chem. Eur. J. 19 (2013) 13484-13491.

[206] Z.L. Fang, S.R. Zheng, J.B. Tan, S.L. Cai, J. Fan, X. Yan, et al., Tubular metal-organic framework-based capillary gas chromatography column for separation of alkanes and aromatic positional isomers, J. Chromatogr. A 1285 (2013) 132138.

[207] J.K. Sun, M. Ji, C. Chen, W.G. Wang, P. Wang, R.P. Chen, et al., A charge-polarized porous metal-organic framework for gas chromatographic separation of alcohols from water, Chem. Commun. 49 (2013) 1624-1626.

[208] H.Y. Huang, C.L. Lin, C.Y. Wu, Y.J. Cheng, C.H. Lin, Metal organic frameworkorganic polymer monolith stationary phases for capillary electrochromatography and nano-liquid chromatography, Anal. Chim. Acta 779 (2013) 96-103.

[209] Y.B. Yu, Y.Q. Ren, W. Shen, H.M. Deng, Z.Q. Gao, Applications of metal-organic frameworks as stationary phases in chromatography, TrAC, Trends Anal. Chem. 50 (2013) 33-41.

[210] J.Q. Xu, J. Zheng, J.Y. Tian, F. Zhu, F. Zeng, C.Y. Su, et al., New materials in solid-phase microextraction, TrAC, Trends Anal. Chem. 47 (2013) 68-83.

[211] J.Y. Tian, J.Q. Xu, F. Zhu, T.B. Lu, C.Y. Su, G.F. Ouyang, Application of nanomaterials in sample preparation, J. Chromatogr. A 1300 (2013) 2-16.

[212] S.L. Yang, C.Y. Chen, Z.H. Yan, Q.Y. Cai, S.Z. Yao, Evaluation of metal-organic framework 5 as a new SPE material for the determination of polycyclic aromatic hydrocarbons in environmental waters, J. Sep. Sci. 36 (2013) 12831290.

[213] Y.L. Hu, C.Y. Song, J. Liao, Z.L. Huang, G.K. Li, Water stable metal-organic framework packed microcolumn for online sorptive extraction and direct analysis of naproxen and its metabolite from urine sample, J. Chromatogr. A 1294 (2013) 17-24.

[214] C. Hu, M. He, B.B. Chen, C. Zhong, B. Hu, Polydimethylsiloxane/metal-organic frameworks coated stir bar sorptive extraction coupled to high performance liquid chromatography-ultraviolet detector for the determination of estrogens in environmental water samples, J. Chromatogr. A 1310 (2013) 21-30. 